\title{
Towards Sophisticated 3D Interphase Modelling of Advanced Bionanocomposites via Atomic Force Microscopy
}

\author{
Mohanad Mousa ${ }^{1,2}$ and Yu Dong $\mathbb{D}^{1}$ \\ ${ }^{1}$ School of Civil and Mechanical Engineering, Curtin University, GPO Box U1987, Perth, WA 6845, Australia \\ ${ }^{2}$ Shatrah Technical Institute, Southern Technical University, Basra, Iraq \\ Correspondence should be addressed to Yu Dong; y.dong@curtin.edu.au
}

Received 15 January 2020; Accepted 13 June 2020; Published 4 August 2020

Academic Editor: Laura Martinez Maestro

Copyright (c) 2020 Mohanad Mousa and Yu Dong. This is an open access article distributed under the Creative Commons Attribution License, which permits unrestricted use, distribution, and reproduction in any medium, provided the original work is properly cited.

\begin{abstract}
Nanomechanical properties and interphase dimensions of PVA bionanocomposites reinforced with halloysite nanotubes (HNTs) and Cloisite 30B montmorillonite (MMT) were evaluated by means of peak force quantitative nanomechanical mapping (PFQNM). A three-phase theoretical composite model was established based on hard-core-soft-shell structures consisting of hard mono-/polydispersed anisotropic particles and soft interphase and matrices. Halpin-Tsai model and Mori-Tanaka model were employed to predict experimentally determined tensile moduli of PVA bionanocomposites where effective volume fraction of randomly oriented nanoparticles resulted from the inclusion of interphase properties and volume fractions. Overall, it was suggested that the estimation of elastic modulus according to effective volume fraction of nanoparticles revealed better agreement with experimental data as opposed to that based upon their nominal volume fraction. In particular, the use of polydispersed HNTs and Cloisite 30B MMT clays with Fuller particulate gradation was proven to yield the best prediction when compared with experimental data among all proposed theoretical models. This study overcomes the neglected real interphase characteristics in modelling nanocomposite materials with much more accurate estimation of their mechanical properties.
\end{abstract}

\section{Introduction}

In the last decade, polymer nanocomposites reinforced with a small amount of nanoparticles with different shapes and sizes in order to enhance multifunctional properties, cost effectiveness, and light-weight structures have become the major focus on the innovation of material development in plastics and composite materials. In a nanocomposite system, there are commonly three major nanofiller shapes including nanoplatelets such as MMT clays and graphene nanoplatelets, nanotubes like carbon nanotubes (CNTs) and HNTs, and nanospheroids including zinc oxide nanoparticles or nanosillica.

The material merit of using a small amount of nanoparticles can significantly enhance mechanical, thermal, electronic, and antimicrobial properties [1-4] with decreased gas/liquid permeability, while some key features of net polymer systems such as low density and easy processibility [5] can still be well implemented. The applications of polymer nanocomposites have been widely expanded in aerospace and aircrafts, automobile manufacturing, food packaging, and medical devices [6]. It is well recognised that an interphase region in the vicinity of nanofillers or nanoparticles in polymer nanocomposites can have a dramatic property change from those of polymer matrices [5], which in turn plays a prevalent role in the overall enhancement of material performance. Interphase dimensions, volume, and properties can be identified as typical features, which depend primarily on matrix-filler interaction associated with nanoparticle structures and shapes in polymer nanocomposites [7]. Such matrix-filler interaction has been investigated by atomistic and coarse-grained molecular simulations [8] though the limitation of a computational environment may often restrict such simulation work to single-particle or two-particle 
systems $[5,8]$. The PFQNM technique has a powerful characterisation capability to obtain the interphase dimensions and properties of nanocomposites based on various nanomechanical properties including elastic modulus and adhesion of nanocomposite constituents along with corresponding dimensions [7].

In simple micromechanical modelling of composite materials using Halpin-Tsai model [9] and Mori-Tanaka model [10], interphase properties and features between fillers and matrices are generally neglected for simplicity. Consequently, the mechanical properties of polymer nanocomposites may be overpredicted based on such conventional composite theoretical models for polymer/CNT composites [11] and silk fibroin/graphene oxide nanocomposites [12], which was consistent with the numerical simulations using the finite element method (FEM) based on the representative volume element (RVE) for polyethylene (PE)/CNT nanocomposites $[13,14]$. On the other hand, such properties can also be underestimated, as evidenced by polyamide 66 (PA66)/calcium carbonate $\left(\mathrm{CaCO}_{3}\right)$ nanocomposites [15]. This drawback can inevitably inhibit accurate micromechanical modelling work in polymer nanocomposite systems owing to the typical lack of interphase properties and features. Despite many recent attempts, the incorporation of interphase regions as the third phase in available MoriTanaka model [16] and Maxwell model [17] reveals little success, arising from the simple assumption that the interphase can be only hypothesised as a $1 \mathrm{D}$ transitional material phase surrounding nanofillers with uniform interphase thickness and regular shapes. Whereas, it has been well documented that an irregular-shaped interphase with nonuniform thickness usually occurs in real morphological structures of composites $[7,18]$.

In particular, when a real interphase effect is taken into account in the modelling work of nanocomposites, interphase volume fraction is one of the key interphase material parameters to be predetermined. With an additional 5 vol\% of monodispersed spherical nanoparticles (particle diameter: $10 \mathrm{~nm}$ and interphase thickness: $0.5 \mathrm{~nm}$ ), the interphase volume fraction can reach as high as $25 \mathrm{vol} \%$, according to Mousa and Dong [7]. When particle diameter is further reduced to be only no more than $5 \mathrm{~nm}$, the interphase volume fraction can be increased by over $50 \mathrm{vol} \%$, as opposed to that of the particles [7]. Amraei et al. [19] established a closedform interphase model as a function of radial distance using RVE, which was found to have the capability of estimating the effective mechanical properties of polymer nanocomposites reinforced with spherical inclusions. For the other work, Amraei et al. [20] particularly concentrated on a closedform micromechanical interphase model in terms of CNT diameter and interphase thickness, as well as the mechanical properties of individual constituents to influence overall mechanical properties of polymer nanocomposites, indicating a critical role of the interphase. Moreover, Zare and Rhee [21] developed a new model to predict the tensile modulus of polymer/clay nanocomposites using not only clay size and morphology but also interfacial shear modulus in good accordance with experimental values for the model validation. The dimensions of clay thickness and length were revealed to be key factors for the enhancement level of nanocomposite modulus. Overall, a holistic understanding for the effect of interphase volume fraction on the elastic modulus of bulk nanocomposites still remains challenging when considering the complexity of interphase structures as well as a potential overlap to neighbouring interfacial layers.

The aim of this study lies in the systematic development of a novel three-phase composite theoretical model by implementing experimentally measured 3D interphase nanomechanical properties in PVA bionanocomposites reinforced with HNTs and Cloisite 30B MMT clays as the most popular tubular and platelet-like clay nanofillers, respectively. Ultimately, missing real interphase characteristics, often encountered in conventional composite modelling approaches, can be recounted (rather than being completely ignored) for accurate property prediction in advanced nanocomposites.

\section{Experimental Work}

2.1. Materials and Fabrication Process. PVA, as a popular water-soluble polymer with a molecular weight of 89000 $98000 \mathrm{~g} / \mathrm{mol}$ and a degree of hydrolysis of $99.0-99.8 \%$, was supplied by Sigma-Aldrich Pty. Ltd., Australia. Cloisite 30B clays modified with methyl, tallow, bis-2-hydroxyethyl, and quaternary ammonium were purchased from Southern Clay Products, Gonzales, TX, USA. HNTs with an outer diameter of 120-140 nm, an inner diameter of $15-100 \mathrm{~nm}$, and a length of $0.3-1.5 \mu \mathrm{m}$ were donated by Imerys Tableware Limited, New Zealand [22].

PVA bionanocomposites reinforced with HNTs and Cloisite 30B clays were synthesised using solution casting following the same procedure mentioned in our previous study [1]. Five $\mathrm{wt} \% / v$ PVA aqueous solution was prepared after mixing PVA powders with deionised water at a magnetic stirring speed of $400 \mathrm{rpm}$ and a processing temperature of $90^{\circ} \mathrm{C}$ for $3 \mathrm{~h}$ to warrant the complete dissolution of PVA. In a similar manner, HNTs and Cloisite 30B clay powders were also mixed in deionised water using a mechanical mixer at $405 \mathrm{rpm}$ and $40^{\circ} \mathrm{C}$ for $2 \mathrm{~h}$. Subsequently, the ultrasonication process was carried out using an ultrasonicating bath (model: ELMA Ti-H-5, IKA; Germany) at an oscillatory frequency of $25 \mathrm{kHz}$ and a power intensity of $70 \%$ at $40^{\circ} \mathrm{C}$ for $1 \mathrm{~h}$. Aqueous suspensions of HNTs and Cloisite 30B clays were gradually added in a dropwise manner into the PVA solution by mechanical mixing in order to obtain particle contents of 0 , 3,5 , and $10 \mathrm{wt} \%$. A further sonication took place for $30 \mathrm{~min}$ to ensure a more uniform particle dispersion. In the end, $20 \mathrm{ml}$ mixed solution was poured on a glass petri dish and subsequently dried in an air-circulating oven at $40^{\circ} \mathrm{C}$ for $48 \mathrm{~h}$. Finally, prepared PVA bionanocomposite films were stored in a desiccator containing silica gels for subsequent material testing and characterisation.

2.2. Material Characterisation via Atomic Force Microscopy (AFM). In this study, the nanomechanical properties of the interphase in PVA bionanocomposites were determined by means of peak force quantitative mapping (PFQM) in a Bruker Dimension FastScan AFM system to acquire a single force-distance curve under ambient conditions. In particular, 
an RTESPA-525A probe (nominal spring constant: $200 \mathrm{~N} / \mathrm{m}$; nominal tip radius: $8 \mathrm{~nm}$; and nominal resonant frequency: $525 \mathrm{kHz}$ ) was employed to facilitate such direct measurements. During the calibration process, the deflection sensitivity was warranted with the acquisition of a force curve on a stiff sapphire-12 surface. The spring constant was determined by using a thermal tuning method [23] in which cantilever mechanical response to thermal agitation was measured with the Brownian motion of encompassing fluid molecules. Imaging analysis using atomic force microscopy (AFM) was carried out with the TESPA probe (normal spring constant: $40 \mathrm{~N} / \mathrm{m}$; tip radius: $8 \mathrm{~nm}$ ). The scan rate was set up at $2 \mathrm{~Hz}$ with a digital pixel resolution of $256 \times 256$. Unwanted features including noise, bow, and tilt were removed when AFM images were first-order flattened using Bruker NanoScope 1.5 software. At least three AFM samples were utilised for each material batch to warrant the test reproducibility.

\section{Modelling Approach}

3.1. 3D Interphase Modulus, Surface Area, and Volume. As mentioned earlier, interphase properties such as interphase modulus and features like interphase surface area and volume were detected via PFQM. The interphase moduli between PVA matrices and dispersed HNTs and Cloisite $30 \mathrm{~B}$ clays in various shapes and sizes were evaluated on the basis of a dataset associated with elastic moduli collected from PVA/HNT and PVA/Cloisite 30B interphases surrounding 75 different particles at 25 line scan regions (LSRs), respectively.

On the other hand, 3D interphase dimensions are classified as interphase width $\mathrm{W}_{\text {Interphase, interphase length }}$

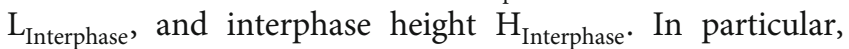
individual interphase width $W_{\text {interphase }}$ interphase length $L_{\mathrm{j} \text { Interphase }}$, and interphase height $H_{k \text { Interphase }}$ along the $i$ th transverse plane $(i=1,2,3 \cdots)$, the $j$ th longitudinal plane $(j=1,2,3 \cdots)$, and $k$ th height plane $(k=1,2,3 \cdots)$, respectively, were measured using the same scanning method mentioned in previous literature [7] so that typical features of distinct interphases between nanoparticles and polymer matrices could be characterised according to the great variation in their nanomechanical properties with the aid of PFQM.

As illustrated in Figures 1(a), 1(b), 1(e), and 1(f) for AFM imaging analysis, it is clearly shown that nanofiller dispersion took place with two typical categories of fully embedded and partially embedded HNTs and Cloisite 30B clays in PVA bionanocomposites. The 3D interphase region can be surrounded between the inner interface area and the outer interface area bound by nanofillers and PVA matrices, respectively, as evidenced in Figures 1(c), 1(d), 1(g), and $1(\mathrm{~h})$. Both surface areas of outer interface $\mathrm{SA}_{\text {outer interface }}$ and inner interface $\mathrm{SA}_{\text {inner interface }}$ with respect to a wide range of fully and partially embedded nanoparticles denoted by subscripts " $\mathrm{f}$ " and " $\mathrm{p}$ " can be estimated in the following by rearranging analytical equations for surface areas of anisotropic particles developed by [24].

$$
\begin{aligned}
\left(\mathrm{SA}_{\text {outer interface }}\right)_{\mathrm{f}}= & a_{1}+b_{1} L_{\text {Interphase }}^{2}+c_{1} W_{\text {Interphase }}^{2} \\
& +d_{1} H_{\text {Interphase }}^{2} \\
\left(\mathrm{SA}_{\text {outer interface }}\right)_{\mathrm{p}}= & a_{2}+b_{2} L_{\text {Interphase-effective }}^{\prime 2} \\
& +c_{2} W_{\text {Interphase-effective }}^{\prime 2} \\
& +d_{2} H_{\text {Interphase-effective }}^{\prime 2} \\
(\mathrm{SA} \text { inner interface })_{\mathrm{f}}= & a_{3}+b_{3} L_{\mathrm{p}}^{2}+c_{3} W_{\mathrm{P}}^{2}+d_{3} H_{\mathrm{P}}^{2}, \\
\left(\mathrm{SA}_{\text {inner interface }}\right)_{\mathrm{p}}= & a_{4}+b_{4} L_{\mathrm{p} \text {-effective }}^{\prime 2}+c_{4} W_{\mathrm{p} \text {-effective }}^{\prime 2} \\
& +d_{4} H_{\mathrm{p} \text {-effective }}^{\prime 2}
\end{aligned}
$$

where under the category of partially embedded nanoparticles shown in Figures $1(\mathrm{~d})$ and $1(\mathrm{~h}), L_{\text {Interphase-effective' }}^{\prime}$ $W_{\text {Interphase-effective, and } H_{\text {Interphase-effective }}^{\prime} \text { are the maximum }}^{\prime}$ length, width, and thickness for effective interphases,

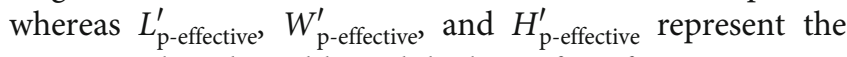
maximum length, width, and thickness for effective nanoparticles (excluding the nanoparticle portions without an interphase to PVA matrices in bionanocomposites). The rest of the letters $a_{i}, b_{i}, c_{i}$, and $d_{i}(i=1,2,3$, and 4$)$ denote empirical constants determined by curve fitting with corresponding experimental data of the surface areas obtained from AFM measurements (see more details in Supporting Information (available here)).

Additionally, with the supply of the aforementioned surface area data in equations (1)-(4), nanoparticle/interphase volume $V_{\mathrm{p} / \text { Interphase }}$ and nanoparticle volume $V_{\mathrm{p}}$ for fully embedded nanoparticles, as well as effective nanoparticle/interphase volume $V_{\mathrm{p} / \text { Interphase-effective }}$ and effective nanoparticle volume $V_{\text {p-effective }}$ for partially embedded nanoparticles can be further determined according to the modified equations derived from Behmer and Hawkins [24]:

$$
\begin{aligned}
& \left(\mathrm{SA}_{\text {outer interface }}\right)_{\mathrm{f}}=e_{1} V_{\mathrm{p} / \text { Interphase, }}^{f_{1}} \\
& \left(\mathrm{SA}{ }_{\text {outer interface }}\right)_{\mathrm{p}}=e_{2} V_{\mathrm{p} / \text { Interphase-effective, }}^{f_{2}} \\
& \left(\mathrm{SA}_{\text {inner interface }}\right)_{\mathrm{f}}=e_{3} V_{\mathrm{p}}^{f_{3}} \\
& \left(\mathrm{SA}_{\text {inner interface }}\right)_{\mathrm{p}}=e_{4} V_{\mathrm{p} \text {-effective. }}^{f_{4}}
\end{aligned}
$$

In a similar manner, empirical constants $e_{i}$ and $f_{i}$ ( $i=1,2,3$, and 4 ) can also be determined using a curvefitting scheme with the experimental data of corresponding volumes via AFM, as given in Supporting Information.

Finally, interphase volume $V_{\text {Interphase }}$ in relation to fully and partially embedded nanoparticles in PVA bionanocomposites depicted in Figure 1 is given by

$$
\begin{aligned}
& \left(V_{\text {Interphase }}\right)_{\mathrm{f}}=V_{\mathrm{p} / \text { Interphase }}-V_{\mathrm{p}}, \\
& \left(V_{\text {Interphase }}\right)_{\mathrm{p}}=V_{\mathrm{p} / \text { Interphase-effective }}-V_{\mathrm{p} \text {-effective }} .
\end{aligned}
$$




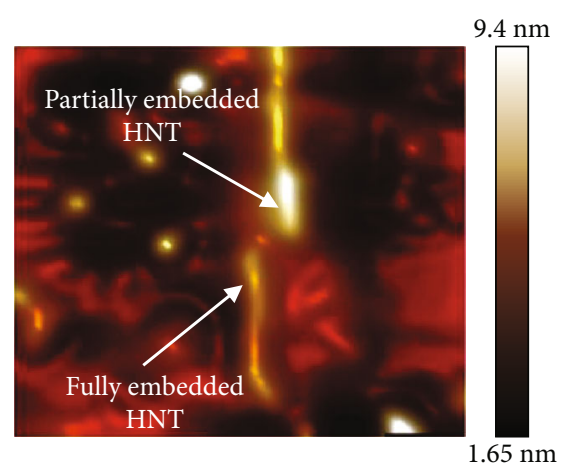

(a)

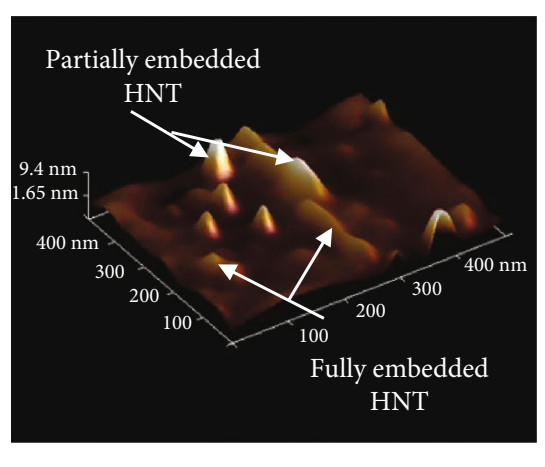

(b)
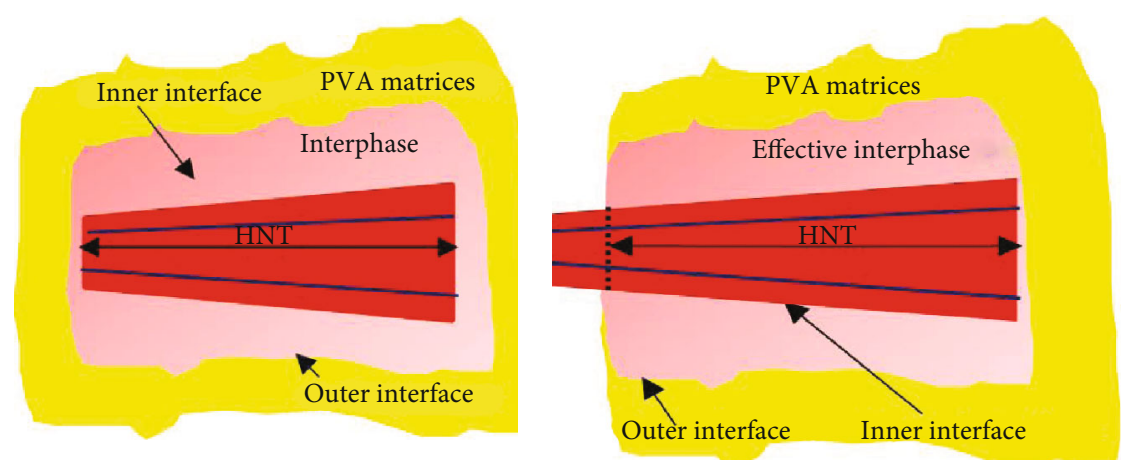

(c)

(d)
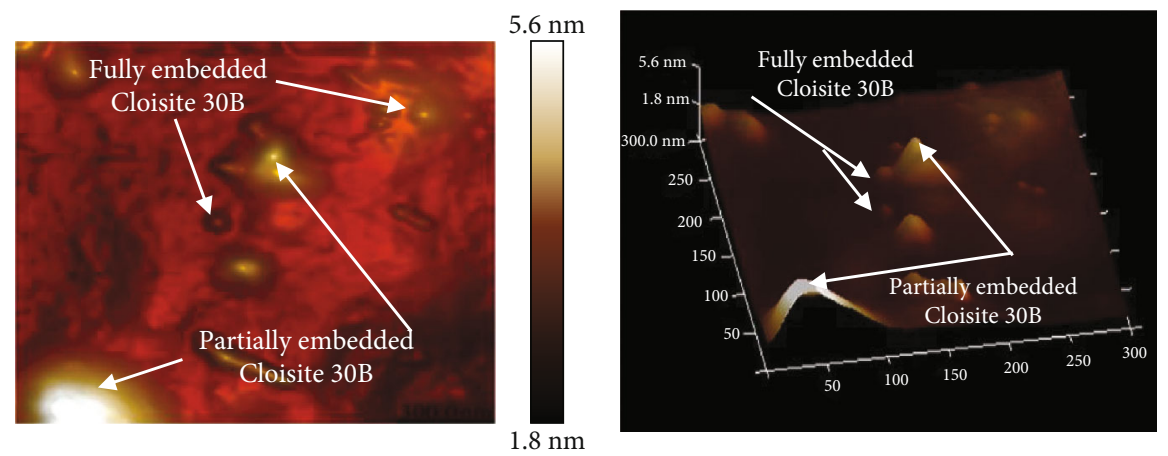

(e)

(f)
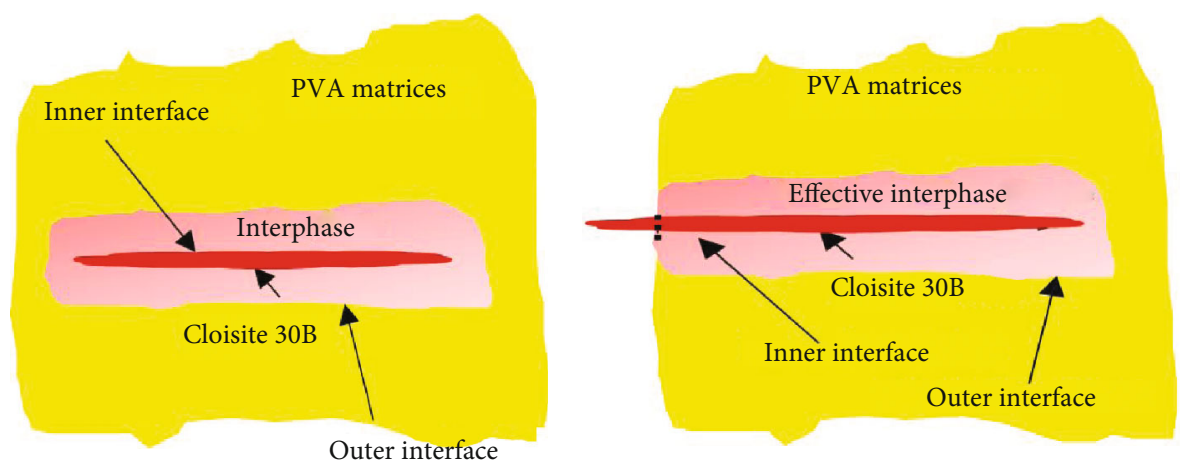

(g)

FIGURE 1: AFM height images of PVA bionanocomposites reinforced with fully embedded and partially embedded HNTs in (a) 2D view and (b) $3 \mathrm{D}$ view as well as corresponding proposed schematic diagrams ( $\mathrm{c}$ and d). AFM height images of PVA bionanocomposites reinforced with fully embedded and partially embedded Cloisite 30B clays in (e) $2 \mathrm{D}$ view and (f) $3 \mathrm{D}$ view as well as corresponding proposed schematic diagrams (g and h). 
3.2. Interphase Volume Fraction. Interphase volume fraction $\varnothing_{\text {Interphase }}$ can be estimated using a nearest-surface distribution theory [25] where composite media consist of 3D rigid anisotropic particles and voids (see Appendix A for more details). In a typical nanocomposite system, uniformly dispersed nanoparticles with relatively similar sizes are known as monodispersed nanoparticles as opposed to polydispersed nanoparticles where more randomly dispersed nanoparticles occur with different sizes and diameters [26]. With respect to a monodispersed particle system, interfacial volume fraction $\varnothing_{\text {Interphase }}$ can be estimated as follows (see more details in Appendix A)

$$
\begin{aligned}
\varnothing_{\text {Interphase }}= & \left(1-\varnothing_{p}\right)\left\{1-\exp \left[-\frac{6 \varnothing_{p} \lambda^{3}}{1-\varnothing_{p}}\left[\frac{1}{S \lambda^{2}}\right.\right.\right. \\
& +\frac{1}{\lambda}\left[2+\frac{3 \varnothing_{p}}{S^{2}\left(1-\varnothing_{p}\right)}\right]+\frac{4}{3}+\frac{4 \varnothing_{p}}{S\left(1-\varnothing_{p}\right)} \\
& \left.\left.\left.+\frac{4 m \varnothing_{p}^{2}}{3 S^{3}\left(1-\varnothing_{p}\right)^{2}}\right]\right]\right\}
\end{aligned}
$$

where $\lambda=t^{\prime} / D_{\mathrm{eq}}$ is the geometric size of anisotropic particles in which $t^{\prime}$ is the interfacial dimension and $D_{\text {eq }}$ is a diameter of a sphere with the same volume of an anisotropic particle. $\varnothing_{p}$ is the nominal volume fraction of nanofillers. $m$ is considered a parameter used for the theoretical estimation of a radial distribution function in a spherical particle system. In this study, $m=2$ has been employed according to the Carnahan-Starling approximation [27]. Here, $S$ is a morphological descriptor of anisotropic particles in terms of their aspect ratio $\alpha$ calculated based on the following:

$$
S=\frac{(1+1.5 \alpha)^{2 / 3}}{1+\alpha}
$$

As far as a polydispersed particle system is concerned, the impact of particle size distribution (PSD) is critical on both the interphase volume fraction and the reinforcement efficiency of nanocomposite systems. The gradation of irregular aggregates can be experimentally evaluated with the aid of a sieve analyser or laser particle analyser in which each irregular aggregate size is assessed relative to a corresponding spherical particle of equivalent size [28]. When an equivalent diameter is determined, the PSD of spherical particles can be transformed into that of anisotropic particles accordingly [29]. Our study focuses on two particulate gradations, namely, the Fuller gradation [30] and the equal volume fraction (EVF) gradation $[29,30]$ in order to estimate the $\varnothing_{\text {Interphase }}$ given as follows:

$$
\varnothing_{\text {Interphase }}=\left(1-\varnothing_{p}\right)\left\{1-\exp \left[-\frac{6 \varnothing_{p}}{\left\langle D_{\mathrm{eq}}^{3}\right\rangle}\left(e^{\prime} t+d^{\prime} t^{3}+\mathrm{g}^{\prime} t^{3}\right)\right]\right\},
$$

$$
\begin{aligned}
e^{\prime}= & \frac{\left\langle D_{\text {eq }}^{2}\right\rangle}{S\left(1-\varnothing_{p}\right)}, \\
d^{\prime}= & \frac{2\left\langle D_{\text {eq }}\right\rangle}{1-\varnothing_{p}}+\frac{3 \varnothing_{p}\left\langle D_{\text {eq }}^{2}\right\rangle^{2}}{S^{2}\left(1-\varnothing_{p}\right)^{2}\left\langle D_{\text {eq }}^{3}\right\rangle}, \\
g^{\prime}= & \frac{4}{3\left(1-\varnothing_{p}\right)}+\frac{4 \varnothing_{p}\left\langle D_{\text {eq }}\right\rangle\left\langle D_{\text {eq }}^{2}\right\rangle}{S\left(1-\varnothing_{p}\right)^{2}\left\langle D_{\text {eq }}^{3}\right\rangle} \\
\left\langle D_{\text {eq }}^{k}\right\rangle= & \int_{D_{\text {min eq }}}^{D_{\text {max eq }} D_{\text {eq }}^{k} f_{N}\left(D_{\text {eq }}\right) d D_{\text {eq }},} \\
f_{N}\left(D_{\text {eq }}\right)= & \frac{4 m \varnothing_{p}\left\langle D_{\text {eq }}^{2}\right\rangle^{3}}{3 S^{3}\left(1-\varnothing_{p}\right)^{3}\left\langle D_{\text {eq }}^{3}\right\rangle^{2}}, \\
& \cdot\left\{\begin{array}{l}
q=2.5 \longrightarrow \text { Fuller gradation } \\
q q
\end{array},\right.
\end{aligned}
$$

where $f_{N}\left(D_{\text {eq }}\right)$ is a number-based probability function of anisotropic particles. $\left\langle D_{\text {eq }}^{k}\right\rangle, D_{\text {eq-min }}$, and $D_{\text {eq-max }}$ are the $k$ th moment and the minimum and maximum equivalent diameters of the anisotropic particles. Finally, the aforementioned parameters to calculate $\varnothing_{\text {Interphase }}$ can then be measured for each nanoparticle based on AFM experimental data. For more detailed derivations of $\varnothing_{\text {Interphase }}$, one can refer to Appendix A.

3.3. Micromechanical Model Based on Nominal and Effective Volume Fractions. The prediction of the elastic moduli of a unidirectionally or randomly distributed filler-reinforced composite is generally achieved by using conventional composite theoretical models such as Halpin-Tsai model [9] or Mori-Tanaka model [10]. In particular, the elastic moduli of our PVA biocomposites in Halpin-Tsai model according to different nanofiller orientation states, namely, randomly oriented and parallel (or well-aligned) nanofillers, can be represented by $E_{\text {random }}$ and $E_{\text {parallel }}$, respectively, using the following:

$$
\begin{aligned}
E_{\text {random }} & =E_{m}\left[\frac{3}{8}\left(\frac{1+\eta_{L} \xi \varnothing_{p}}{1-\eta_{L} \varnothing_{p}}\right)+\frac{5}{8}\left(\frac{1+2 \eta_{T} \varnothing_{p}}{1-\eta_{T} \varnothing_{p}}\right)\right], \\
E_{\text {parallel }} & =E_{m}\left[\frac{1+\eta_{L} \xi \varnothing_{p}}{1-\eta_{L} \varnothing_{p}}\right], \\
\eta_{L} & =\frac{\left(E_{p} / E_{m}\right)-1}{\left(E_{p} / E_{m}\right)+\xi}
\end{aligned}
$$




$$
\begin{aligned}
& \eta_{T}=\frac{\left(E_{p} / E_{m}\right)-1}{\left(E_{p} / E_{m}\right)+2}, \\
& \xi=\frac{2 \alpha}{3}=\frac{2 \imath_{p}}{3 t_{p}}, \\
& \varnothing_{p}=\frac{W_{p}}{W_{p}+\left(\rho_{p} / \rho_{m}\right)\left(1-W_{p}\right)},
\end{aligned}
$$

where $E_{m}$ and $E_{p}$ are Young's moduli of PVA matrices and nanoparticles (i.e., HNTs and Cloisite 30B clays), accordingly. $l_{p}$ and $t_{p}$ refer to the length and thickness of nanoparticles. $\varnothing_{p}$ and $W_{p}$ are nominal volume fraction and weight fraction of nanofillers in PVA bionanocomposites, respectively, while $\rho_{p}$ and $\rho_{m}$ are the densities of nanoparticles and PVA.

Furthermore, Mori-Tanaka model is an effective theoretical model to predict the elastic moduli of polymer composites, which is also employed in modelling our PVA bionanocomposites. It was originally employed by Tandon and Weng [31] using Mori-Tanaka theory [10] and Eshelby's solution [32] to derive a complete analytical solution for calculating the elastic moduli of an isotropic matrix containing aligned spheroidal inclusions. Longitudinal and transverse moduli of polymer composites $\left(E_{11}\right)$ and $\left(E_{22}\right)$ can be experessed as follows:

$$
\begin{aligned}
& \frac{E_{11}}{E_{m}}=\frac{1}{1+\emptyset_{p}\left(A_{1}+2 v_{m} A_{2}\right) / A} \\
& \frac{E_{22}}{E_{m}}=\frac{1}{1+\emptyset_{p}\left(-2 v_{m} A_{3}+\left(1-v_{m}\right) A_{4}+\left(1+v_{m}\right) A_{5} A\right) / 2 A},
\end{aligned}
$$

where $v_{m}$ is Poisson's ratio of polymer matrices and $A_{i}$ ( $i=1-5)$ and $A$ are the functions of Eshelby's tensors and properties of the matrices and fillers such as Young's moduli, Poisson's ratio, aspect ratio, and volume fraction of fillers. When fillers are inclined to more random orientation, the elastic modulus of composites can be further predicted by using a combination of the laminate theory [33] and MoriTanaka model given by

$$
E_{c} \cong 0.375 E_{11}+0.625 E_{22} \text {. }
$$

In a nanocomposite system, large specific surface areas of nanofillers yield more amounts of polymeric molecular chains to attach to nanofiller surfaces resulting in more effective interphases of nanocomposites. Accordingly, the nominal volume fraction of nanofillers may be altered when reinforced within polymer matrices in nanocomposite systems. It has been proven that the effective volume fraction of nanofillers $\varnothing_{p}^{\prime}$ is more applicable instead for accurate property estimation in modelling work using the following $[32,34,35]$ :

$$
\varnothing_{p}^{\prime}=\varnothing_{p}\left(1+k x R_{g} A_{T} \rho_{p}\right)
$$

where $R_{g}$ is the radius gyration of a polymer, while $A_{T}$ is the specific surface area of nanofillers. The layer thickness of absorbed polymeric chains in nanoparticles is $x R_{g}$, which means increasing up to $x$ times of $R_{g}$. The alteration of $k x$ depends on interfacial interaction levels between polymer matrices and nanoparticles in different nanocomposite systems. Additionally, the dynamic behaviour of polymeric chains near an attractive interface may vary from that of a bulk polymer phase and the effect of attractive surfaces can take place for distances larger than $R_{g}$ for polymers [36]. The term of $k x$ can be reconsidered based on the following $[31,33]$ :

$$
k x=\frac{E_{m}}{E_{p}}\left(\frac{t}{R_{g}}\right)
$$

where $t$ is regarded as the thickness of adsorbed layers.

The effective volume fraction of nanofillers $\varnothing_{p}^{\prime}$ in PVA/HNT bionanocomposites can be determined using equation (28) in a general form. However, in polymer/platelete nanocomposites, $\varnothing_{p}^{\prime}$ should depend on intercalation and exfoliation levels of platelet-like nanofillers taking place within polymer matrices. With respect to clay intercalated structures in nanocomposites [31], $\varnothing_{p}^{\prime}$ can be calculated using the following derived equation:

$$
\frac{1}{\varnothing_{p}^{\prime}}=1+\frac{\rho_{p}^{\prime}\left(1-W_{p}^{\prime}-W_{p}^{\prime} W_{p}^{\prime \prime} s\right)\left[d_{1}(N-1)+h\right]}{W_{p}^{\prime} \rho_{m}\left[d_{2}(N-1)+h\right]},
$$

where $\rho_{p}^{\prime}$ is referred to as the clay density, $W_{p}^{\prime}$ is the weight fraction of clays in nanocomposites, and $W_{p}^{\prime \prime}$ is the weight fraction of clay platelets within clays. $s$ is the polymer uptake in a general expression $s=\left(1-W_{p}^{i}\right) / W_{p}^{i}$ to represent the mass of polymer matrices swollen into the unit mass of intercalated clays, where $W_{p}^{i}$ is the weight fraction of intercalated clay structures. $d_{1}$ and $d_{2}$ are basal plane spacing values of asreceived clay particles and intercalated clays in nanocomposites, respectively. $N$ and $h$ are the average layer number per stack and thickness of a single platelet, respectively.

In the case of exfoliated clay structures in nanocomposites where individual clay platelets are dispersed homogeneously in polymer matrices with an adsorption effect, $\varnothing_{p}^{\prime}$ can be calculated according to equation (28) in a rewritten form below:

$$
\varnothing_{p}^{\prime}=\varnothing_{p}\left(1+k x R_{g} A_{T p} \rho_{p}^{\prime \prime}\right)
$$

where $A_{T p}$ is the total surface area and $\rho_{p}^{\prime \prime}$ is the density of single clay platelets by replacing $A_{T}$ and $\rho_{p}$ accordingly in equation (28). 


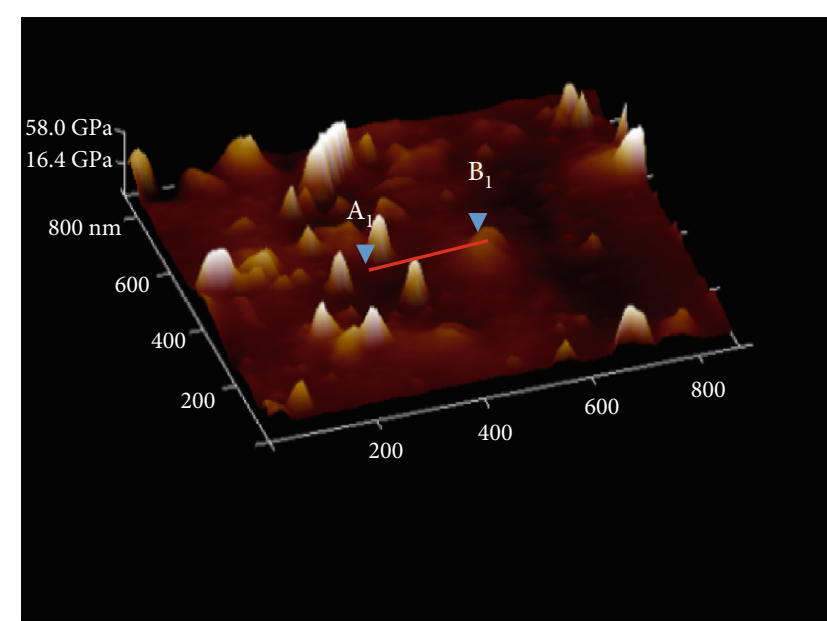

(a)

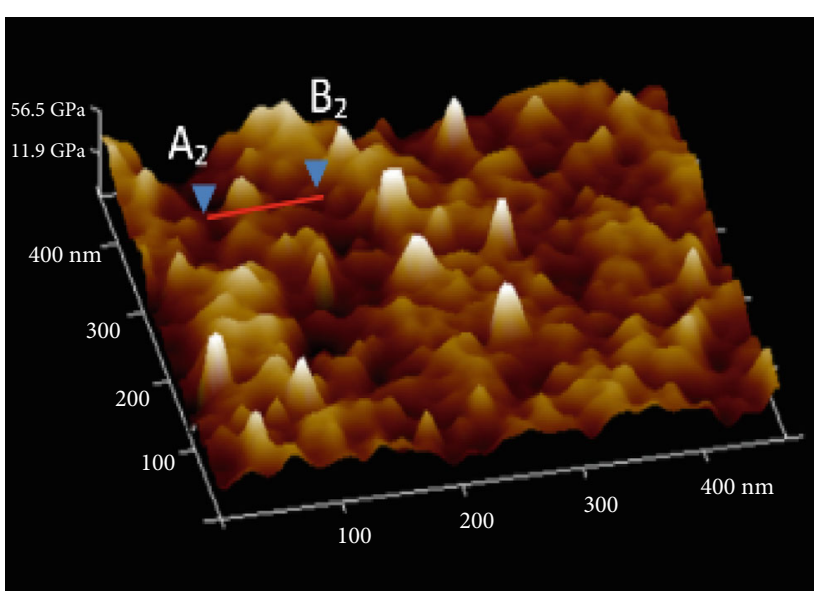

(c)

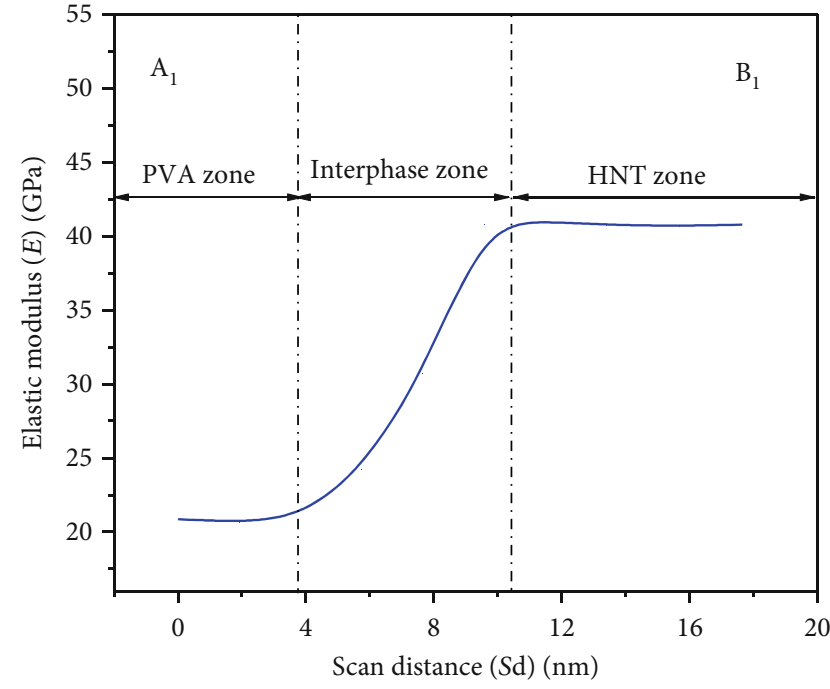

(b)

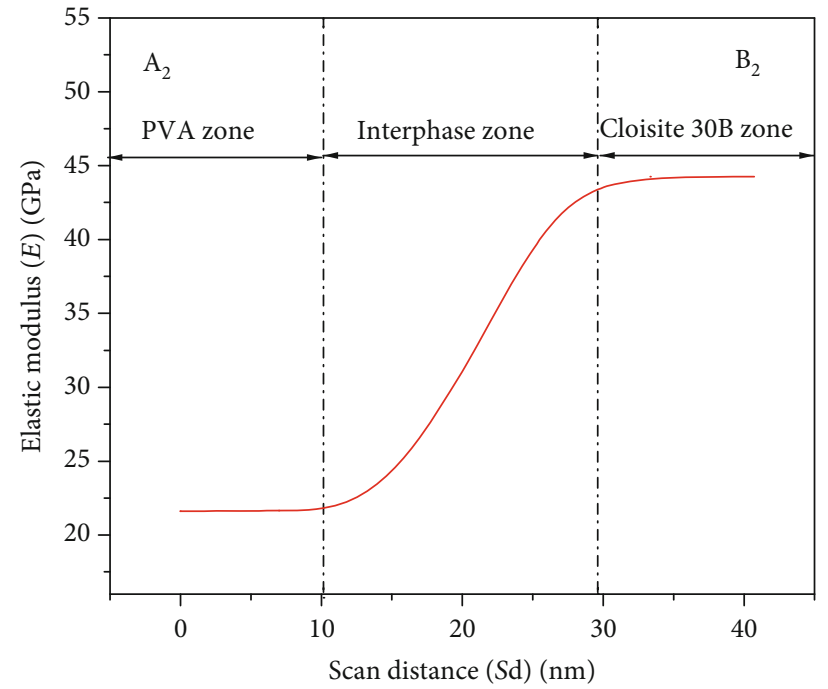

(d)

FIGURE 2: 3D AFM mapping images and corresponding typical profile of elastic modulus in PVA/3 wt\% HNT bionanocomposites (a and b), as well as PVA $/ 3 \mathrm{wt} \%$ Cloisite $30 \mathrm{~B}$ clay bionanocomposites, respectively. $\mathrm{A}_{1} \mathrm{~B}_{1}$ and $\mathrm{A}_{2} \mathrm{~B}_{2}$ are the corresponding typical cut sections for scan distance Sd.

3.4. Volume Fraction of Nanofillers with Interphase Effect. The interphase features and properties are essential in a nanocomposite system, which is often ignored in conventional modelling work. The interphases in PVA bionanocomposites generally have nonuniform dimensions and critical nanomechanical properties to significantly influence nanofiller-matrix interactions. For example, by increasing the interphase volume from 2988 to $4363 \mathrm{~nm}^{3}$ in PVA/nanodiameter bamboo charcoal (NBC) bionanocomposites, their interphase modulus was found to be remarkably enhanced from 34.67 to $49.91 \mathrm{GPa}$ (i.e., an increase by $44 \%$ ) [7]. Consequently, the application of $3 \mathrm{D}$ interphase features such as interphase size and volume fraction to predict the elastic modulus of polymer nanocomposites may yield a more reliable modelling approach to estimate bulk nanocomposite properties according to their nanomechanical behaviour.
Apparently, the volume fractions of nanoparticles and interphase $\varnothing_{p}$ and $\varnothing_{\text {Interphase }}$ in a nanocomposite system can be expressed as follows:

$$
\begin{gathered}
\varnothing_{p}=\frac{V_{p}}{V_{c}}, \\
\varnothing_{\text {Interphase }}=\frac{V_{\text {Interphase }}}{V_{c}},
\end{gathered}
$$

where $V_{c}$ and $V_{\text {Interphase }}$ are the volumes of nanocomposites and interphase, respectively. In this case, $V_{p}$ and $V_{\text {Interphase }}$ can be estimated by using equations (7) and (9) accordingly. 


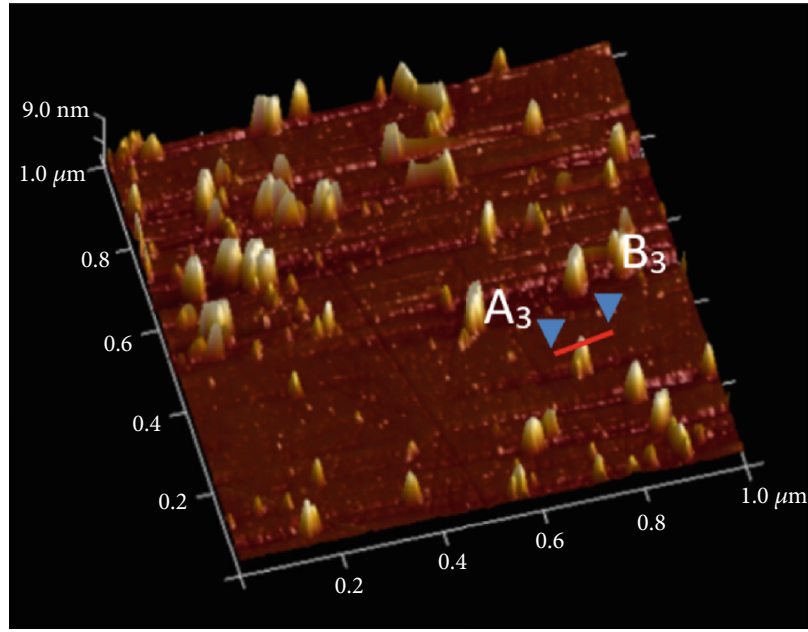

(a)

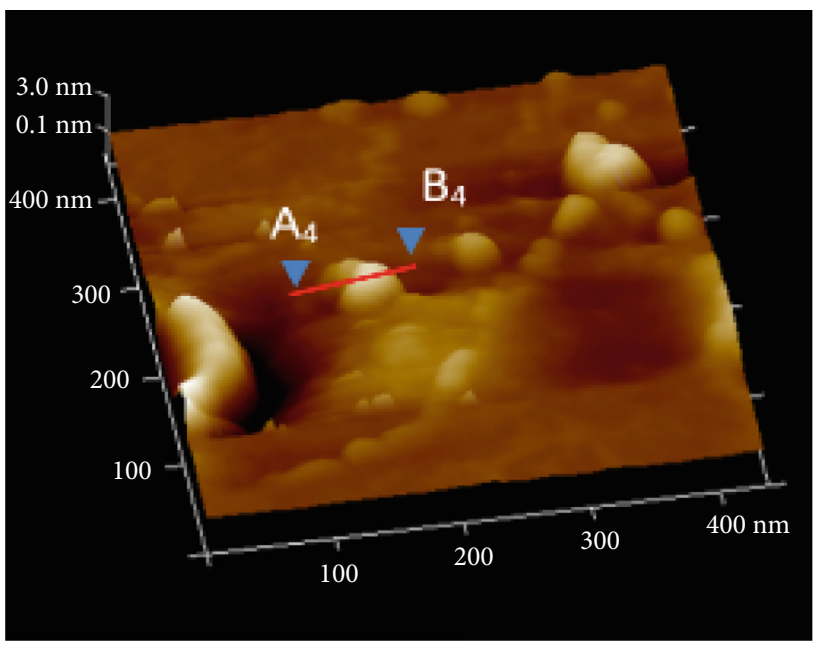

(c)

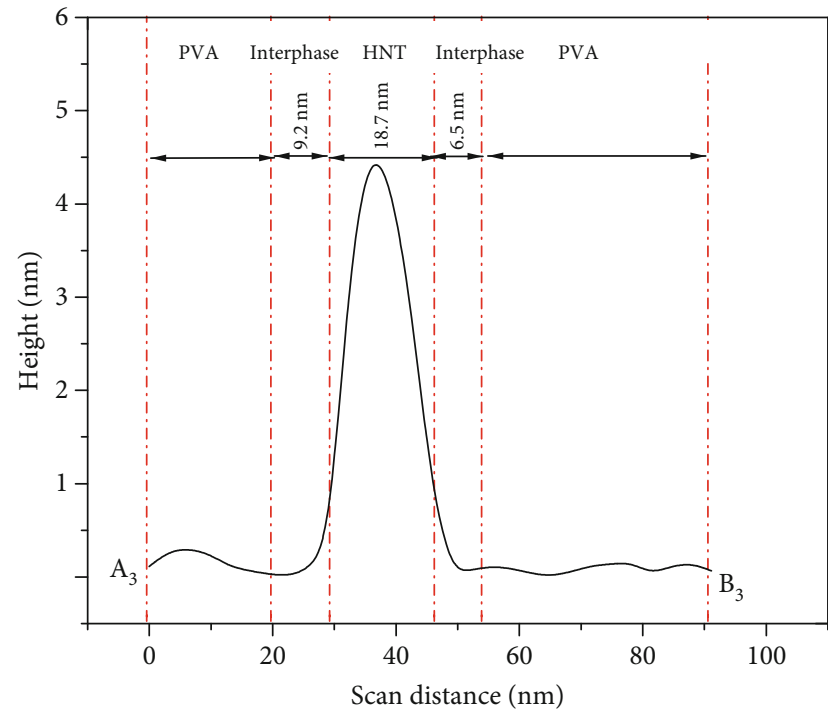

(b)

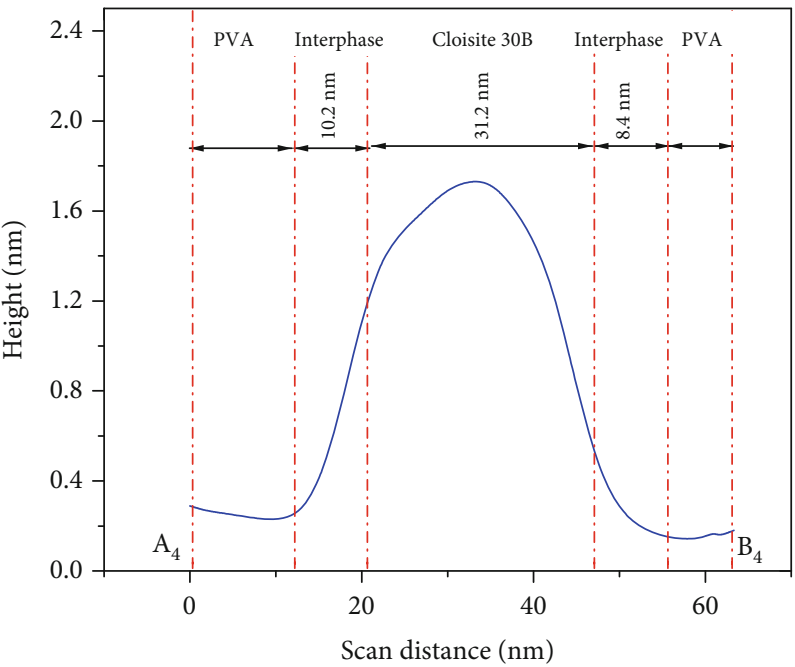

(d)

Figure 3: 3D AFM height mapping images and typical height profiles of PVA/3 wt\% HNT bionancomposites (a and b) and PVA/3 wt\% Cloisite $30 \mathrm{~B}$ clay bionanocomposites (c and d), respectively. $\mathrm{A}_{3} \mathrm{~B}_{3}$ and $\mathrm{A}_{4} \mathrm{~B}_{4}$ are the corresponding typical cut sections for scan distance.

By rearranging equations ((32)) and ((33)), they yield a new proposed equation based on the interphase features shown as follows:

$$
\varnothing_{p}=\frac{\varnothing_{\text {Interphase }} V_{p}}{V_{\text {Interphase }}},
$$

where $\varnothing_{\text {Interphase }}$ can be determined according to the theory of the nearest-surface function [25] elaborated in Section 3.2.

\section{Results and Discussion}

4.1. Elastic Properties of Interphase. As seen from Figure 1, both HNTs and Cloisite $30 \mathrm{~B}$ clays when dispersed into PVA matrices in bionanocomposites presented two similar nanoparticle-embedding effects, namely fully embedded and partially embedded formations. When nanoparticles are fully embedded into continuous matrices, a full interphase configuration is manifested in Figures $1(\mathrm{c})$ and $1(\mathrm{~g})$, while an effective interphase (also known as partial interphase without the consideration of noninteracting nanoparticle portions) is generally applied under the scenario of partial embedding in Figures 1(d) and 1(h) leading to different levels of filler-matrix interaction and reinforcement efficiency to impact the interphase modulus.

Furthermore, as a typical case, the AFM images and profiles of the elastic modulus for PVA/HNT bionanocomposites and PVA/Cloisite 30B clay bionanocomposites at a nanofiller content of $3 \mathrm{wt} \%$ are depicted in Figure 2. The final interphase modulus was determined by using the best curve fitting to discrete modulus datasets based on 25 


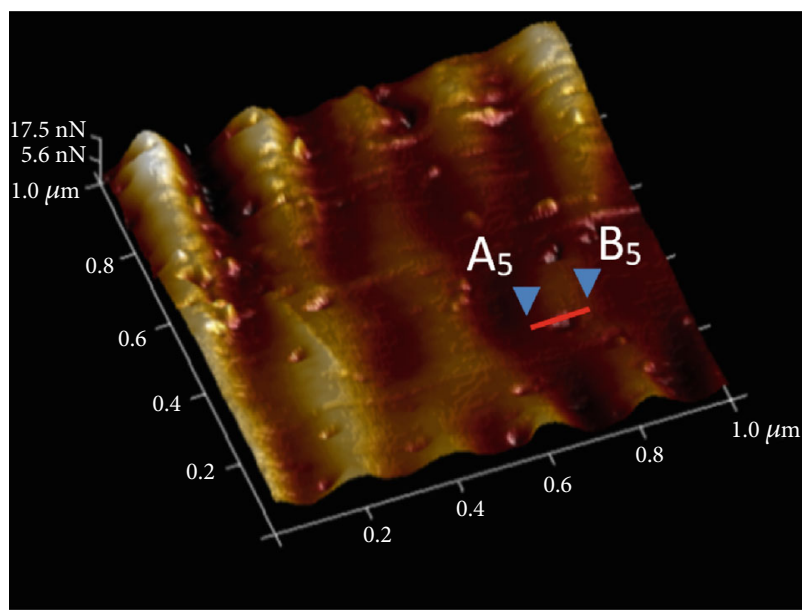

(a)

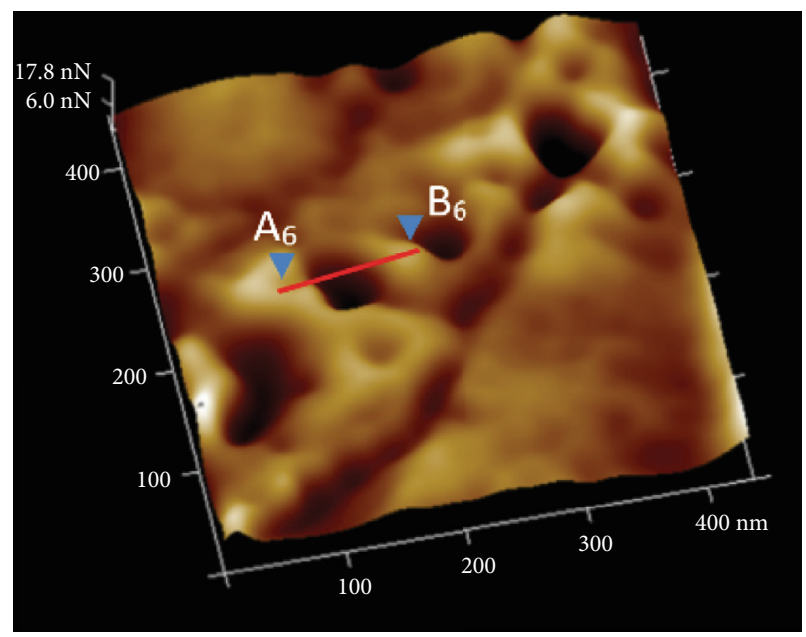

(c)

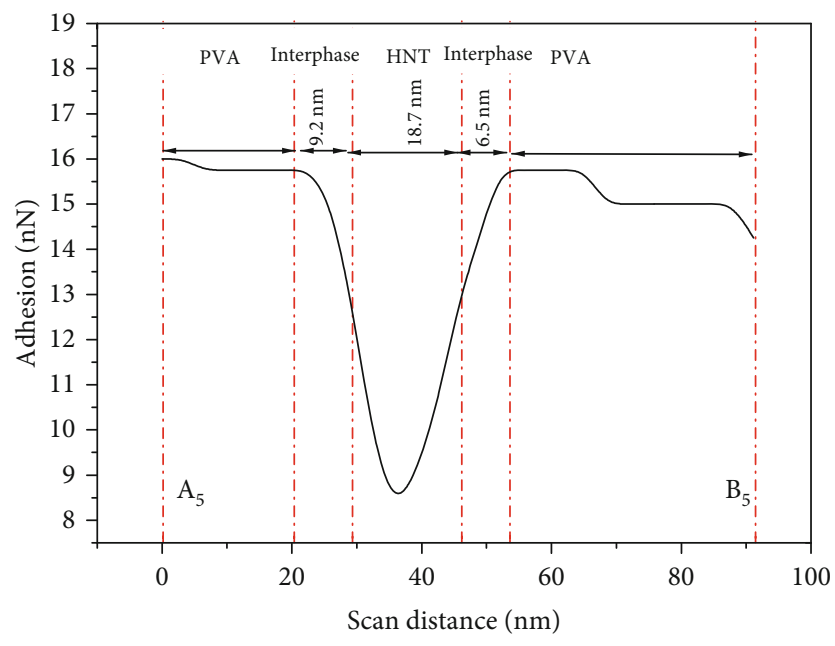

(b)

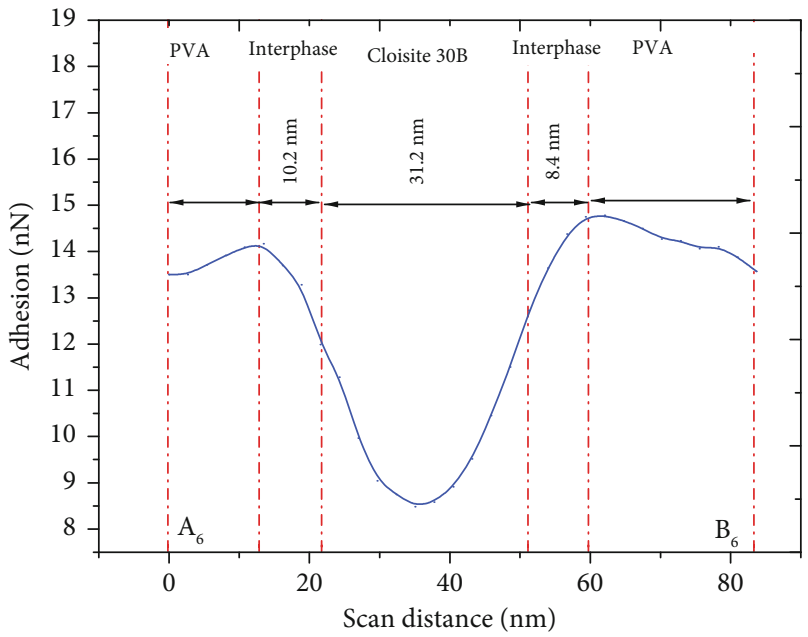

(d)

Figure 4: 3D AFM adhesion mapping images and typical adhesion profiles of PVA/3wt\% HNT bionanocomposites (a and b) and PVA $/ 3$ wt $\%$ Cloisite $30 \mathrm{~B}$ clay bionanocomposites (c and d), respectively. $A_{5} B_{5}$ and $A_{6} B_{6}$ are the corresponding typical cut sections for scan distance.

representative line scan regions (LSRs) illustrated in Figure S9 in Supporting Information. Overall, the interphase modulus demonstrated an almost linearly increasing trend with a modulus-gradient effect in terms of scan distance except for the interphase boundary regions around nanoparticles and PVA matrices regardless of additional HNTs and Cloisite 30B clays in PVA bionanocomposites. In comparison, the interphase modulus of PVA/Cloisite 30B clay bionanocomposites was increased from $20.6 \pm 3.4$ $\mathrm{GPa}$ near PVA matrices to $41.6 \pm 4.6 \mathrm{GPa}$ surrounding nanoclays as opposed to the variation of the interphase modulus in the range from $22.2 \pm 2.9$ to $43.4 \pm 3.1 \mathrm{GPa}$ in PVA/HNT bionanocomposites accordingly (Figures 2(b) and $2(\mathrm{~d})$ ). However, the interphase moduli measured for PVA bionanocomposites in this study were less than those of silk fibroin (SF)/graphene oxide (GO) nanocomposites in the range of approximately $10-250 \mathrm{GPa}$ [12] as well as those of epoxy/T300 carbon nanocomposites between 23 and $90 \mathrm{GPa}$ [17]. Such variations in the interphase modulus as well as the modulus-gradient effect in the interphase zones from nanoparticles to polymer matrices may be associated with the gradient number of hydrogen bonding from nanofiller surfaces to polymer matrices, which is believed to play an important role in tailoring the mechanical properties of polymer nanocomposites $[37,38]$. In a similar manner, Amraei et al. [19, 20] also identified interphase transitional zones with the continuous variations of elastic modulus between the inclusions and matrices with the assumption of a perfect bonding effect in terms of radial distance of RVE in a nanocomposite system. 


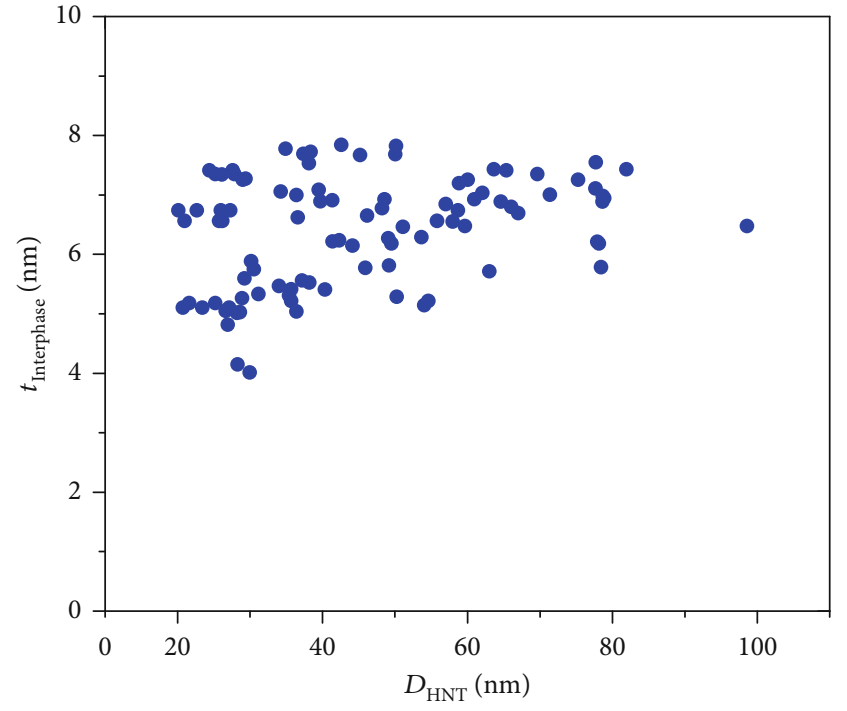

(a)

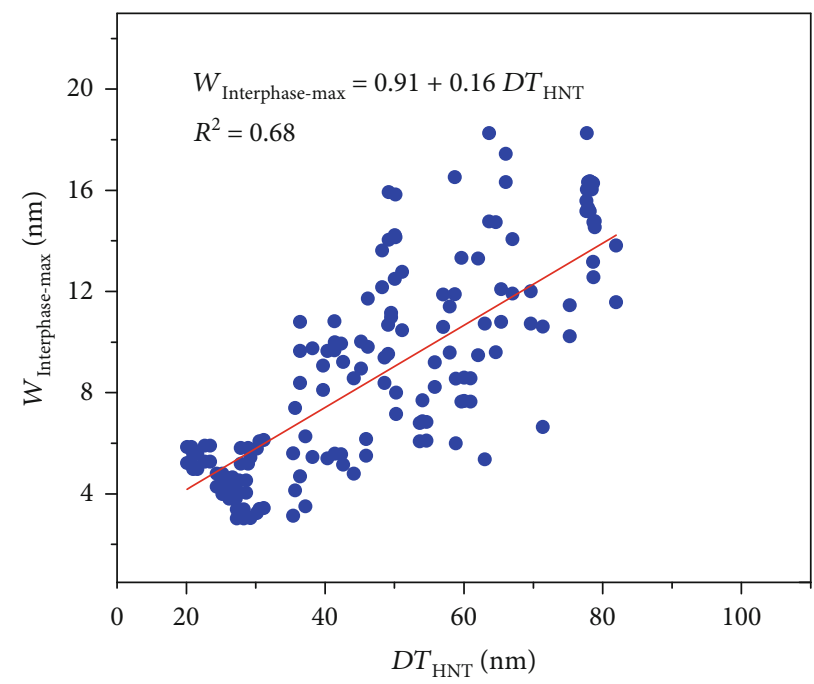

(c)

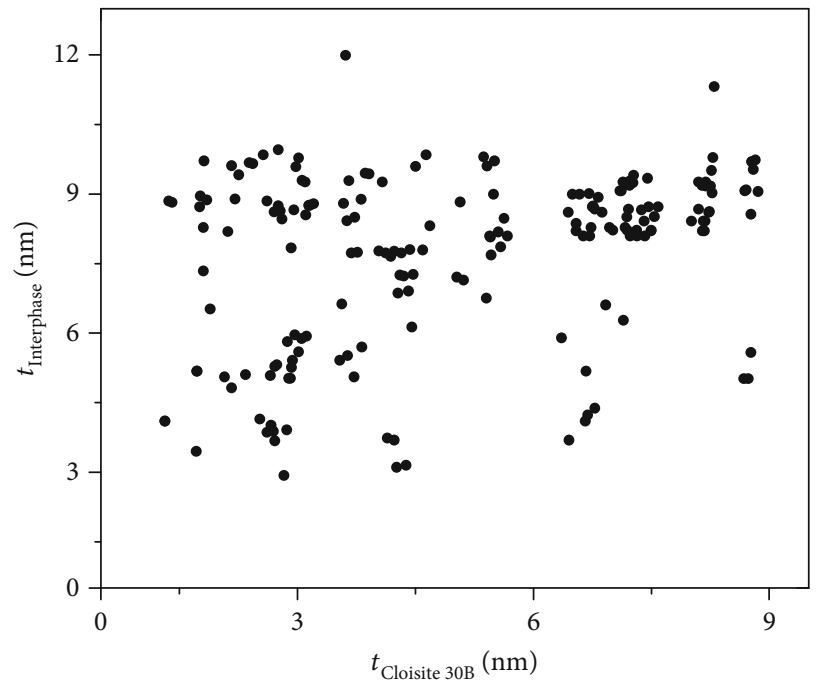

(e)

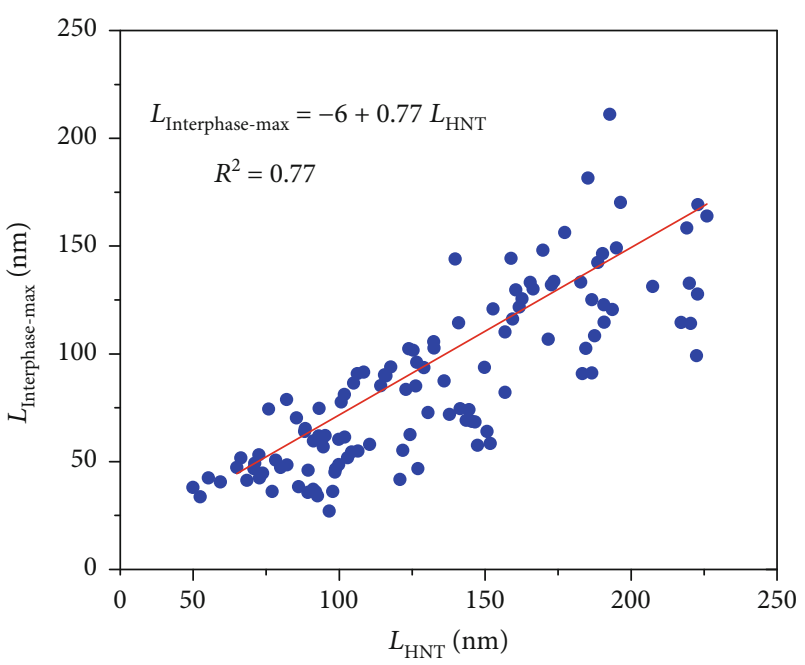

(b)

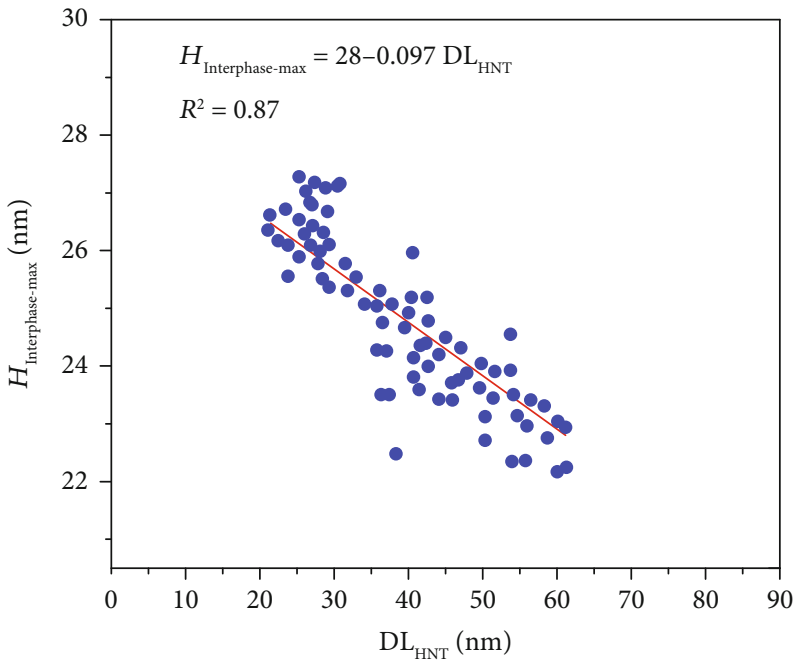

(d)

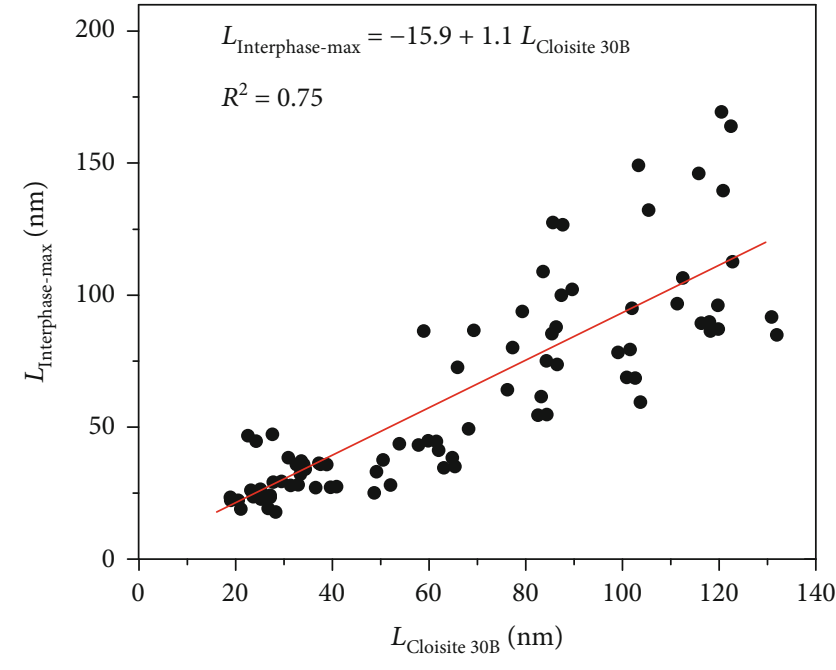

(f)

Figure 5: Continued. 


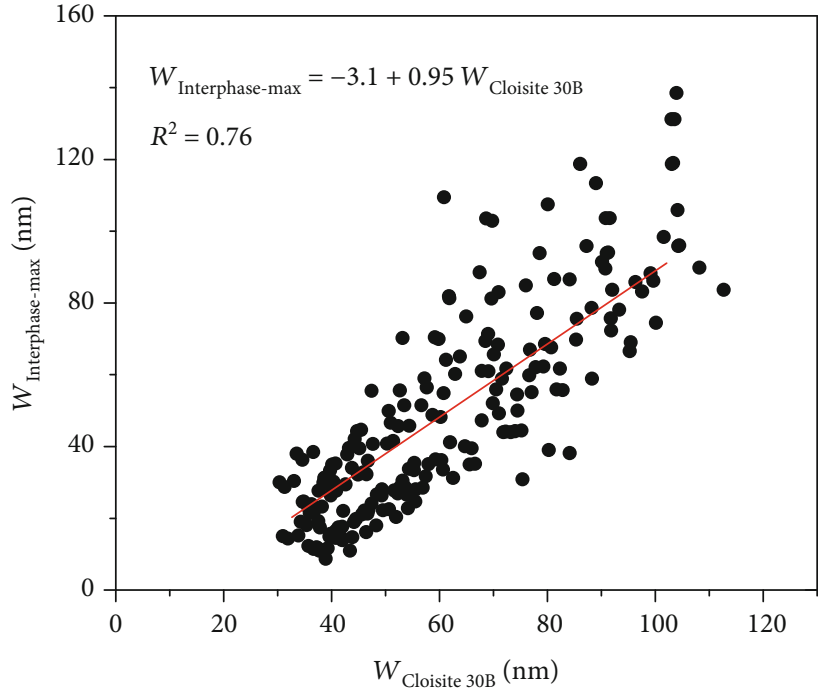

(g)

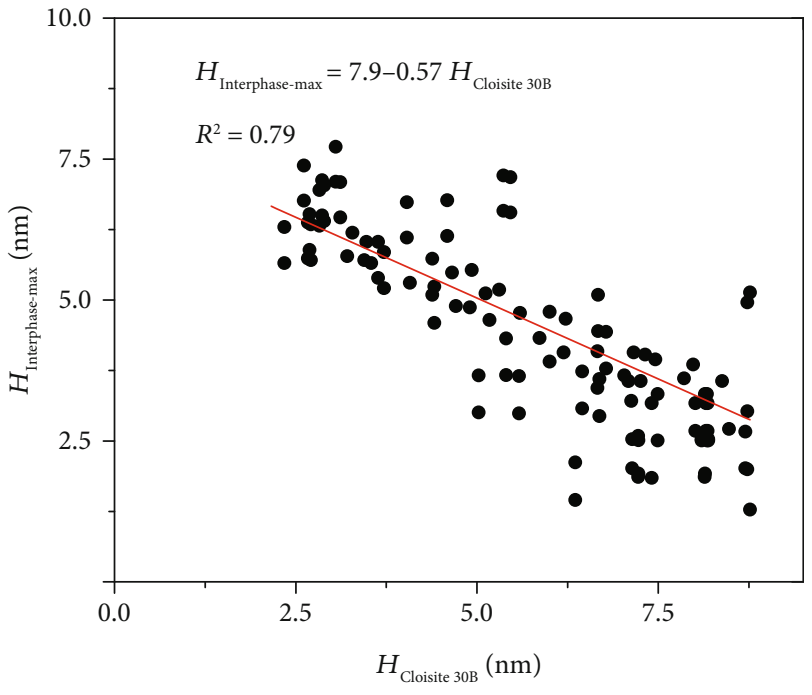

(h)

FIGURE 5: Correlation between maximum interphase dimensions and nanofiller dimensions of PVA/HNT bionanocomposites and PVA/Cloisite $30 \mathrm{~B}$ clay bionanocomposites: (a) $t_{\text {Interphase }}$ vs. $D_{\mathrm{HNT}}$, (b) $L_{\text {Interphase-max }}$ vs. $L_{\mathrm{HNT}}$, (c) $W_{\text {Interphase-max }}$ vs. $\mathrm{DT}$ HNT, $(\mathrm{d})$ $H_{\text {Interphase-max }}$ vs. $\mathrm{DL}_{\mathrm{HNT}}$, (e) $t_{\text {Interphase }}$ vs. $t_{\text {Cloisite 30B }}$, (f) $L_{\text {Interphase-max }}$ vs. $L_{\text {Cloisite 30B }}$, (g) $W_{\text {Interphase-max }}$ vs. $W_{\text {Cloisite 30B }}$, and (h) $H_{\text {Interphase-max }}$ vs. $H_{\text {Cloisite 30B }} \cdot t_{\text {Interphase }}$ is interphase thickness, and $D_{\text {HNT }}$ is HNT diameter. $L_{\text {Interphase-max, }}, W_{\text {Interphase-max }}$, and $H_{\text {Interphase-max }}$ are maximum interphase length, width, and height, respectively. $L_{\mathrm{HNT}}, \mathrm{DL}_{\mathrm{HNT}}$, and $\mathrm{DT}_{\mathrm{HNT}}$ are the length, longitudinal diameter, and transverse diameter of HNTs while $L_{\text {Cloisite } 30 \mathrm{~B}}, W_{\text {Cloisite } 30 \mathrm{~B}}$, and $t_{\text {Cloisite } 30 \mathrm{~B}}$ are the length, width, and thickness of Cloisite $30 \mathrm{~B}$ clay platelets.

4.2. Interphase Dimensions. The elastic properties of interphases in composite materials generally vary to a different extent when surrounded with individual particles or fillers in diverse sizes and shapes, thus resulting in the great change of interphase dimensions. Interphase dimensions can be clearly specified according to the variation identified in terms of height and adhesion profiles in PVA bionanocomposites reinforced with $3 \mathrm{wt} \%$ HNTs and Cloisite 30B clays, as depicted in Figures 3 and 4, respectively. Interphase thickness was determined to be 6.5 and $9.2 \mathrm{~nm}$ on both sides of HNTs as opposed to corresponding relatively large dimensions of 8.4 and $10.2 \mathrm{~nm}$ on those of Cloisite $30 \mathrm{~B}$ clays, which appeared to be consistent in view of both height and adhesion profiles. Moreover, the tip adhesion to PVA matrices was detected to be approximately $14.24 \pm 2.31 \mathrm{nN}$ and became greater than those of HNTs and Cloisite 30B clays at $8.6 \pm$ 1.08 and $8.4 \pm 1.1 \mathrm{nN}$, respectively. As clearly seen, the adhesion force of PVA matrices was much greater than those for HNTs and Cloisite 30B clays, which could be explained by more hydroxyl groups identified in PVA when compared to those of HNTs and Cloisite 30B clays.

Overall, interphase dimensions of PVA bionanocomposites reinforced with HNTs and Cloisite 30B clays revealed very similar tendencies in terms of interphase thickness $t_{\text {Interphase }}$, maximum interphase length $L_{\text {Interphase-max }}$, maximum interphase width $W_{\text {Interphase-max }}$, and maximum interphase height $H_{\text {Interphase-max }}$ from a $3 \mathrm{D}$ point of view displayed in Figure 5. In particular, $t_{\text {Interphase }}$ appeared to be independent of the HNT diameter $\left(D_{\mathrm{HNT}}\right)$ and platelet thickness of Cloisite 30B $\left(t_{\text {Cloisite 30B }}\right)$, respectively (Figures $5(\mathrm{a})$ and $5(\mathrm{e}))$. Nonetheless, both $L_{\text {Interphase-max }}$ and $W_{\text {Interphase-max }}$ increased in a linear manner as a function of HNT length $L_{\mathrm{HNT}}$ and HNT transverse diameter $\mathrm{DT}_{\mathrm{HNT}}$ in PVA/HNT bionanocomposites, as well as Cloisite $30 \mathrm{~B}$ clay platelet length $L_{\text {Cloisite 30B }}$ and width $W_{\text {Cloisite 30B }}$ accordingly in Figures $5(\mathrm{~b})$, 5(c), 5(f), and 5(g) despite opposite linearly decreasing trends taking place in $H_{\text {Interphase-max }}$ in terms of HNT longitudinal diameter $\mathrm{DL}_{\mathrm{HNT}}$ and $H_{\text {Cloisite 30B }}$ depicted in Figures 5(d) and 5(h). Such a phenomenon can be ascribed to an increase in the contact surface areas between continuous polymer matrices and more dispersed nanoparticles in a nanocomposite system especially when nanoparticles are fully embedded or covered by surrounding matrices [6]. Increasing $\mathrm{DL}_{\mathrm{HNT}}$ or $H_{\text {Cloisite 30в }}$ could make it difficult for nanofillers to be fully embedded within polymer matrices, thus resulting in the reduction in $H_{\text {Interphase-max }}$.

As demonstrated in Figure 1 for the proposed mechanism models in terms of nanofiller dispersion and particlematrix interaction, it is worthwhile investigating these two typical scenarios, namely the fully and partially embedded nanoparticles with PVA matrices in bionanocomposites for the assessment of their interphase modulus. The former apparently yields more effective interphases around each side of nanoparticles (i.e., full coverage of nanoparticles by interphases), which is generally deemed as a good representation of effective load transfer from matrices and nanofillers, while the latter gives rise to less pronounced interphase effectiveness since some remarkable portions of nanoparticles were detected to be free of contact with PVA matrices, further reducing effective interfacial regions. In this study, the interphase surface area $\mathrm{SA}_{\text {Interface }}$ and interphase volume $V_{\text {Interphase }}$ were characterised as two critical 

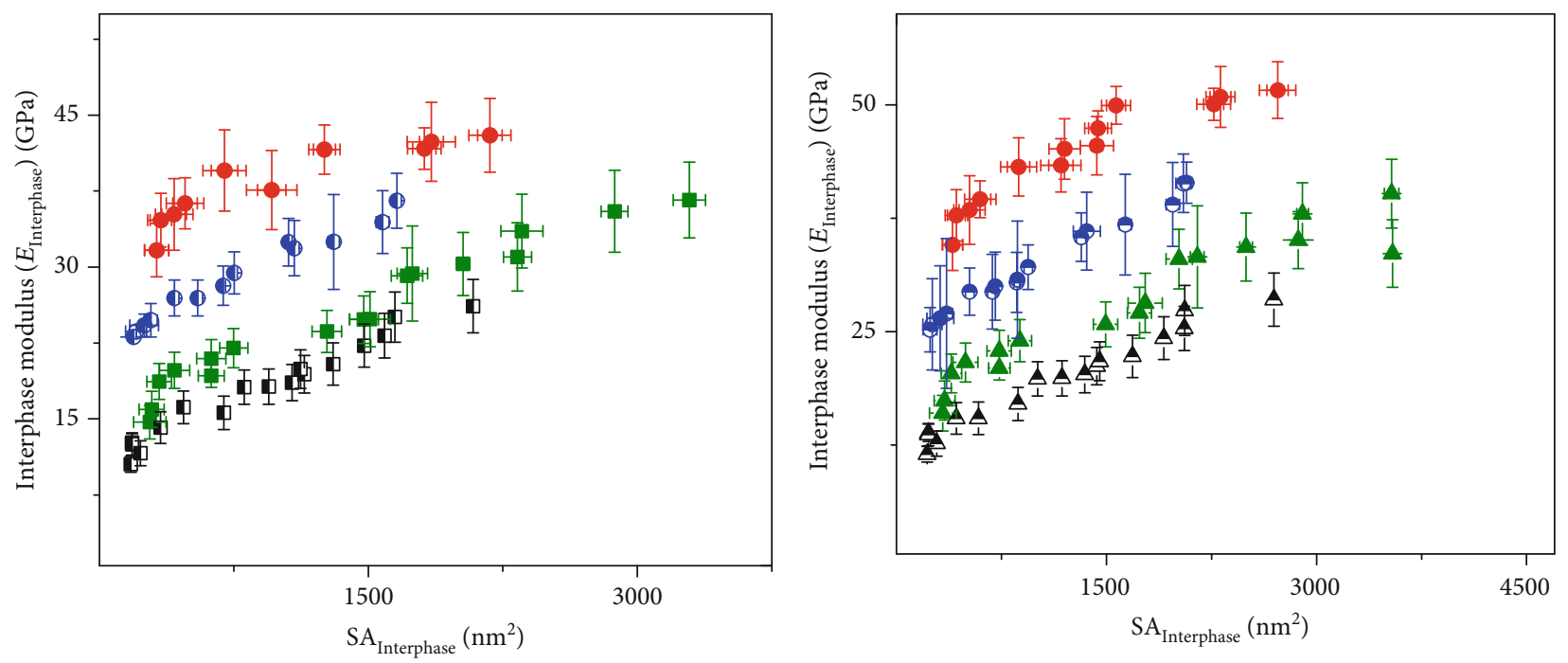

- Inner interface-fully embedded HNT

- Inner interface-partially embedded HNT

- Outer interface-fully embedded HNT

- Outer interface-partially embedded HNT

(a)

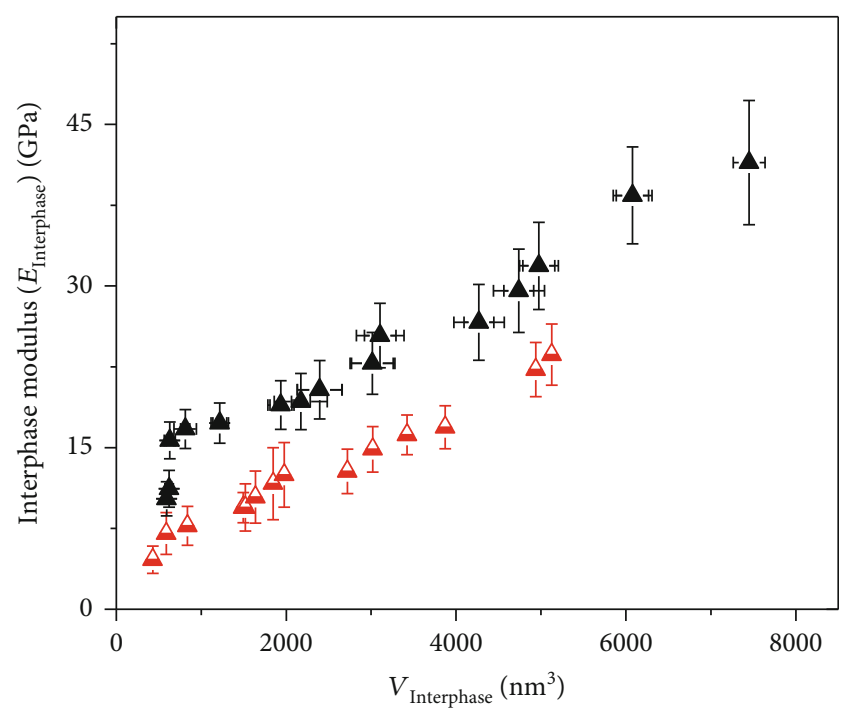

- Fully embedded HNT

$\Delta$ Partially embedded HNT

- Inner interface-fully embedded Cloisite 30B

- Inner interface-partially embedded Cloisite 30B

A Outer interface-fully embedded Cloisite 30B

$\Delta$ Outer interface-partially embedded Cloisite 30B

(b)

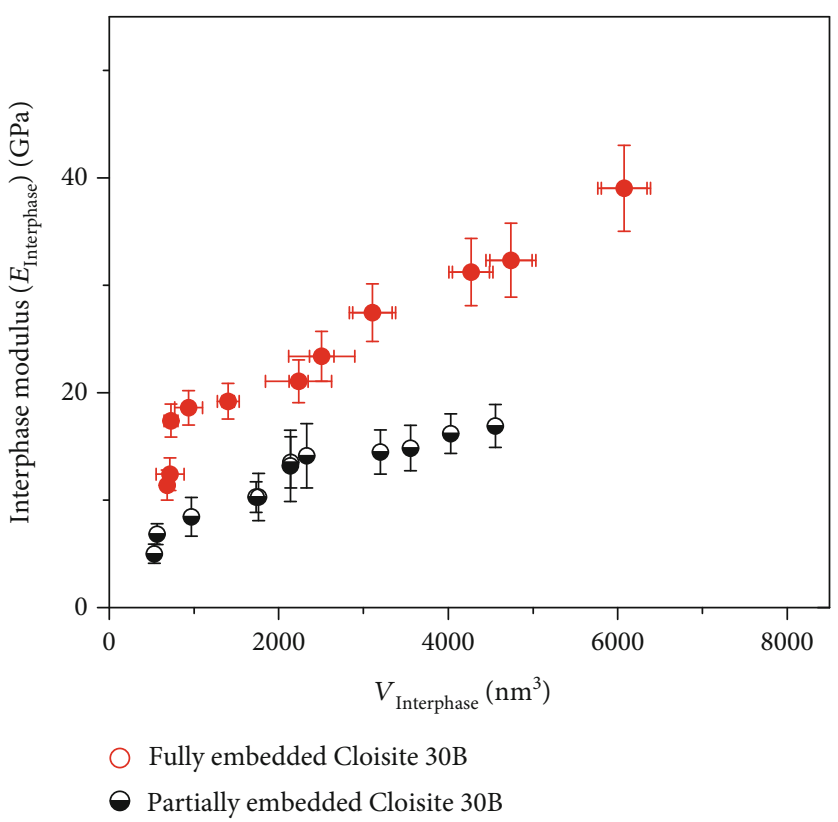

(d)

FIGURE 6: Relationships between interphase modulus $E_{\text {Interphase }}$ and interphase surface area $S_{\text {Interphase }}$ (a) PVA/HNT bionanocomposites and (b) PVA/Cloisite $30 \mathrm{~B}$ clay bionanocomposites. Relationships between interphase modulus $E_{\text {Interphase }}$ and interphase volume $V_{\text {Interphase }}$ : (c) PVA/HNT bionanocomposites and (d) PVA/Cloisite 30B clay bionanocomposites.

interphase dimensional parameters to evaluate the impacts on interphase modulus $E_{\text {Interphase }}$ with respect to fully or partially embedded nanoparticles in PVA bionanocomposites (Figure 6). In addition, $\mathrm{SA}_{\text {Interface }}$ is further divided into $\mathrm{SA}_{\text {inner interface }}$ and $\mathrm{SA}_{\text {outer interface }}$ when considering the inner interfaces between nanoparticles and interphase regions, as well as outer interfaces between the interphase regions and PVA matrices, respectively, as illustrated in Figures 1(c), $1(\mathrm{~d}), 1(\mathrm{~g})$, and $1(\mathrm{~h})$. A very identical behaviour occurred in
PVA/HNT bionanocomposites and PVA/Cloisite 30B clay bionanocomposites, which indicated that overall $E_{\text {Interphase }}$ tended to be consistently enhanced in a nonlinear manner with increasing $\mathrm{SA}_{\text {Interface }}$ and $V_{\text {Interphase }}$ individually. More consistently, fully embedded HNTs and Cloisite 30B clays yielded higher $E_{\text {Interphase }}$ as opposed to those based on partially embedded counterparts. Besides, $\mathrm{SA}_{\text {inner interface }}$ led to relatively high overall $E_{\text {Interphase }}$ as opposed to those based

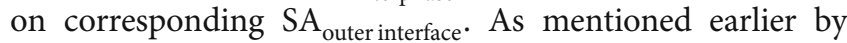




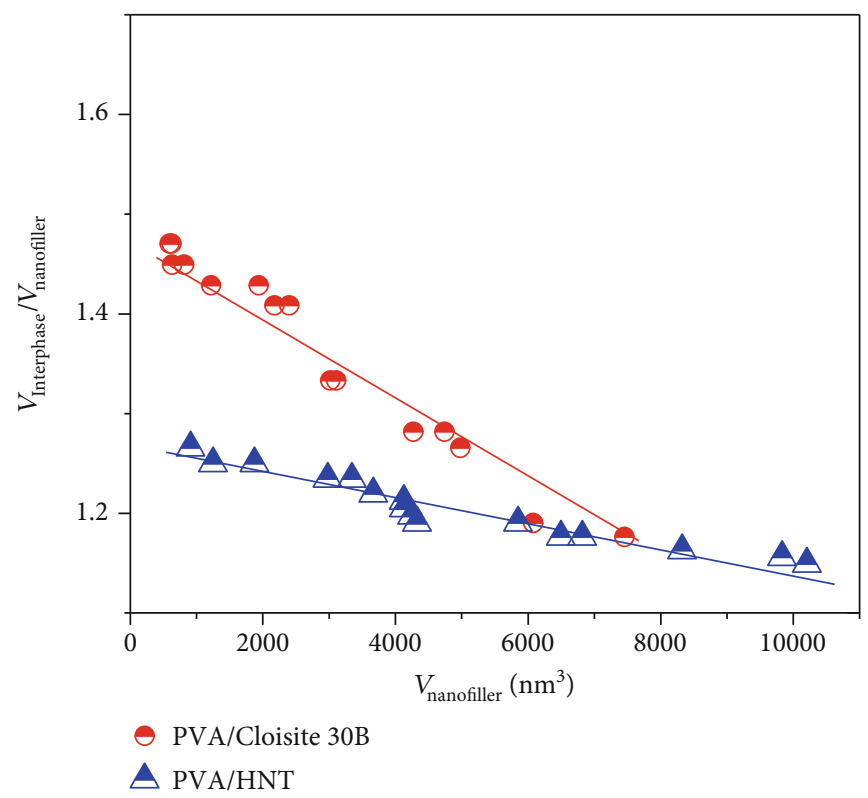

FIGURE 7: Interphase volume per unit nanofiller volume $\left(V_{\text {Interphase }} / V_{\text {nanofiller }}\right)$ as a function of $V_{\text {nanofiller }}$ in PVA bionanocomposites reinforced with HNTs and Cloisite 30B clays.

Liu et al. [39], the interphase region with a modulus gradient effect can be divided into two different zones comprising the first zone in contact with nanoparticle areas with relatively high interphase density as opposed to the second zone adjacent to matrix regions. Fan et al. [40] reported that increasing interphase density certainly induced the modulus increase in a nanostructure-specific hierarchy in good accordance with our higher $E_{\text {Interphase }}$ in the case of $\mathrm{SA}_{\text {inner interface }}$ in PVA bionanocomposites. The abovementioned results may suggest that $\mathrm{SA}_{\text {Interface }}$ and $V_{\text {Interphase }}$ as typical $2 \mathrm{D}$ and $3 \mathrm{D}$ interphase dimensional parameters can play a vital role in the improvement of $E_{\text {Interphase }}$ leading to the further enhancement in mechanical properties of PVA bionanocomposites. Nevertheless, it is also admittedly mentioned here that partially embedded nanoparticles with the imperfect bonding effect within PVA matrices are inevitably detrimental to their mechanical properties with much less bonded matrix-filler interactions when compared with fully embedded counterparts.

On the other hand, the aspect ratio is used as an important factor to evaluate the reinforcement efficiency of nanofillers within polymer matrices in nanocomposites. Its determination becomes much easier when dealing with nanofillers with regular sizes and shapes. However, irregular nanofillers with different shapes are quite common leading to the complexity of real aspect ratios due to the effect of multistage dispersion processing techniques generally used in the manufacture of nanocomposites $[25,26]$. Moreover, in addition to the nanofiller aspect ratio, interphase dimensions and properties can also be affected by nanofiller dispersion [26]. Liu and Brinson [5] as well as Alishahi et al. [41] suggested the use of interphase volume per unit nanofiller volume ( $V_{\text {Interphase }} / V_{\text {nanofiller }}$ ) in theoretical modelling as an effective parameter in promoting the reinforcement efficiency of nanofillers instead of $V_{\text {Interphase }}$, whose relationship as a function of $V_{\text {nanofiller }}$ was presented in Figure 7 in this study. Overall, an increase in $V_{\text {nanofiller }}$ caused a significant decrease in $V_{\text {Interphase }} / V_{\text {nanofiller }}$ for both PVA bionanocomposites despite being more pronounced in PVA/Cloisite 30B clay bionanocomposites. This is because Cloisite $30 \mathrm{~B}$ clay platelets induced more efficient planar reinforcements when compared to predominant longitudinal reinforcement of tubular HNTs.

4.3. Particle Debonding. With an increase in nanoparticle loading, interparticle spacing appeared to be smaller and nanoparticles tended to be interconnected with neighbouring counterparts side by side with some nanoparticles free of contact with PVA matrices in bionanocomposites. Moreover, a closely compacted joint particle-to-particle pattern may induce adverse phase separation resulting in scattered load transfer from PVA matrices to nanoparticles. It was evidently shown in Figures 8(a) and 8(c) that large HNT aggregates and clustered stack-up Cloisite $30 \mathrm{~B}$ clays took place at a very high nanofiller content up to $10 \mathrm{wt} \%$ in PVA bionanocomposites with the resulting weak interfacial bonding for particle-matrix interactions. Two narrow zones near interphase regions were highlighted with a sharp decline in elastic modulus for both PVA bionanocomposites with excessive amounts of undispersed nanoparticles in Figures 8(b) and $8(d)$, indicating an existing particle debonding effect with polymer matrices [36]. A lower interphase modulus may also arise from a relatively low density near interphase zones as compared to those of aggregated nanoparticles and polymer matrices [24]. In addition to nanoparticle sizes and dimensions, nanoparticle dispersion within continuous matrices is also among the key factors in controlling the interfacial bonding between fillers and matrices. When 

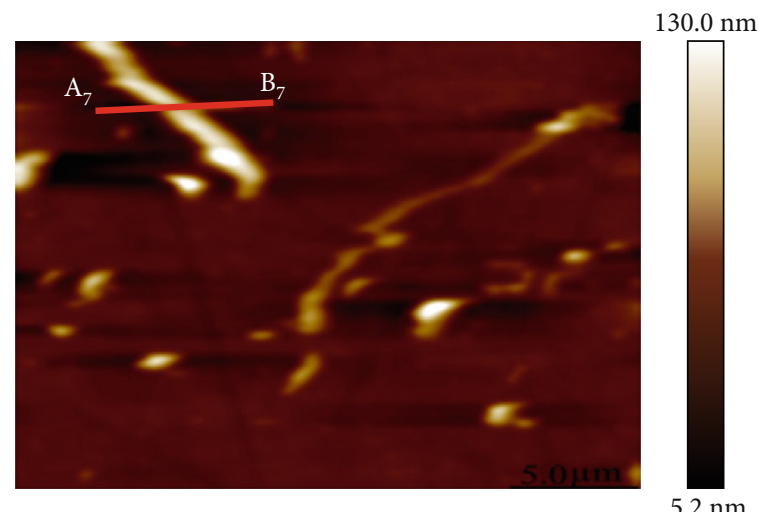

(a)

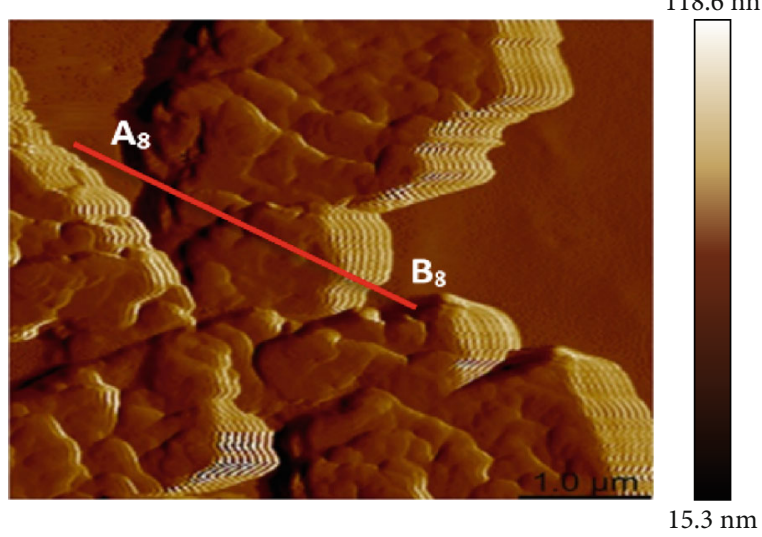

(c)

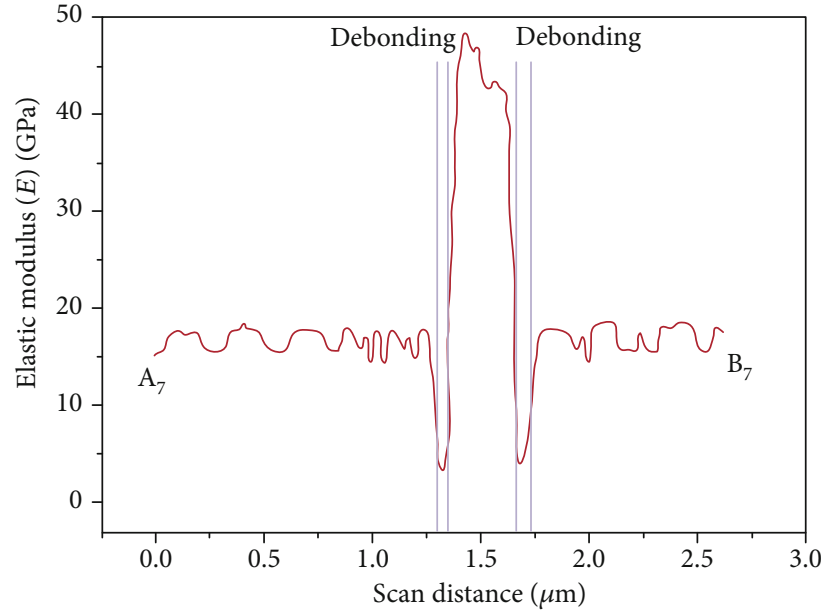

(b)

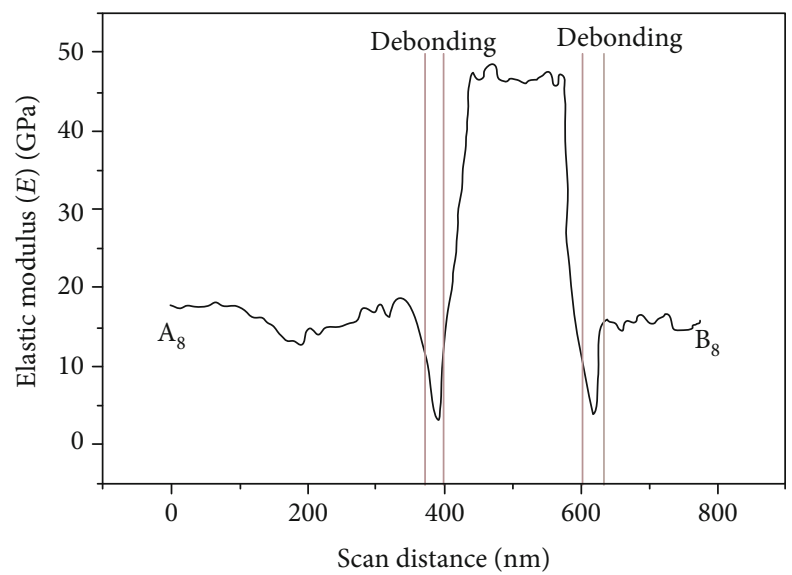

(d)

FIGURE 8: AFM height mapping images and corresponding typical elastic modulus profiles of (a and b) PVA/10wt\% HNT bionanocomposites, as well as (c and $\mathrm{d}$ ) PVA/10 wt\% Cloisite $30 \mathrm{~B}$ clay bionanocomposites indicating phase separation and agglomeration of nanoparticles, respectively. $\mathrm{A}_{7} \mathrm{~B}_{7}$ and $\mathrm{A}_{8} \mathrm{~B}_{8}$ are corresponding typical cut sections for scan distance.

excessive amounts of HNTs and Cloisite 30B clays were dispersed within PVA matrices, those nanoparticles tended to agglomerate owing to their weak Van der Waals interactions, while higher nanofiller content inevitably led to a significant reduction in interparticle spacing to hinder uniform nanoparticle dispersion [42, 43]. A nanofiller fine dispersion method such as ultrasonication [41], on the other hand, may give rise to the possible damage of nanoparticle structures especially at the high ultrasonic power intensity resulting instead in declined mechanical properties of bionanocomposites.

\subsection{Prediction of Elastic Moduli of PVA Bionanocomposites.} The prediction of the elastic moduli of PVA bionanocomposites reinforced with HNTs and Cloisite 30B clays as a function of nominal and effective volume fractions of nanoparticles was presented in Figure 9 (without predefined particle systems) and Figure 10 (with monodispersed and polydispersed particle systems), respectively, using HalpinTsai model, Mori-Tanaka model, and a combination of
Mori-Tanaka model and laminate theory [4] along with associated modelling parameters listed in Table 1 . In both bionanocomposites (without predefined particle systems), the estimated moduli did not coincide well with corresponding experimental data even at the very low volume fractions of HNTs and Cloisite 30B clays, Figure 9. However, the use of an effective volume fraction and a randomly oriented dispersion state of nanoparticles consistently gave rise to much closer correlation with experimental data regardless of the composite theoretical models implemented, as also confirmed in previous studies [34, 35]. In particular, with respect to PVA/Cloisite 30B clay bionanocomposites, the predicted results appeared to be in better agreement with experimental data at the low volume fraction of $0.061 \mathrm{vol} \%$ on the basis of an effective volume fraction and exfoliated clay structures, while better correlation was manifested for those predicted in terms of effective volume fraction and intercalated clay structures at high volume fraction levels. As far as morphological structures are concerned, it was expected that the majority of the Cloisite $30 \mathrm{~B}$ clay platelets tended to be more 


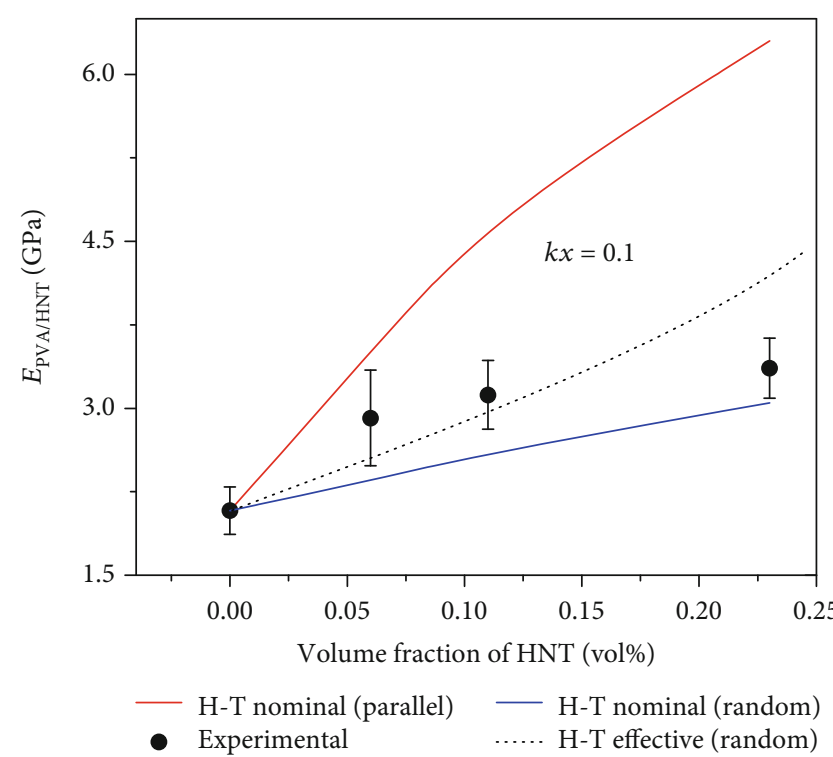

(a)

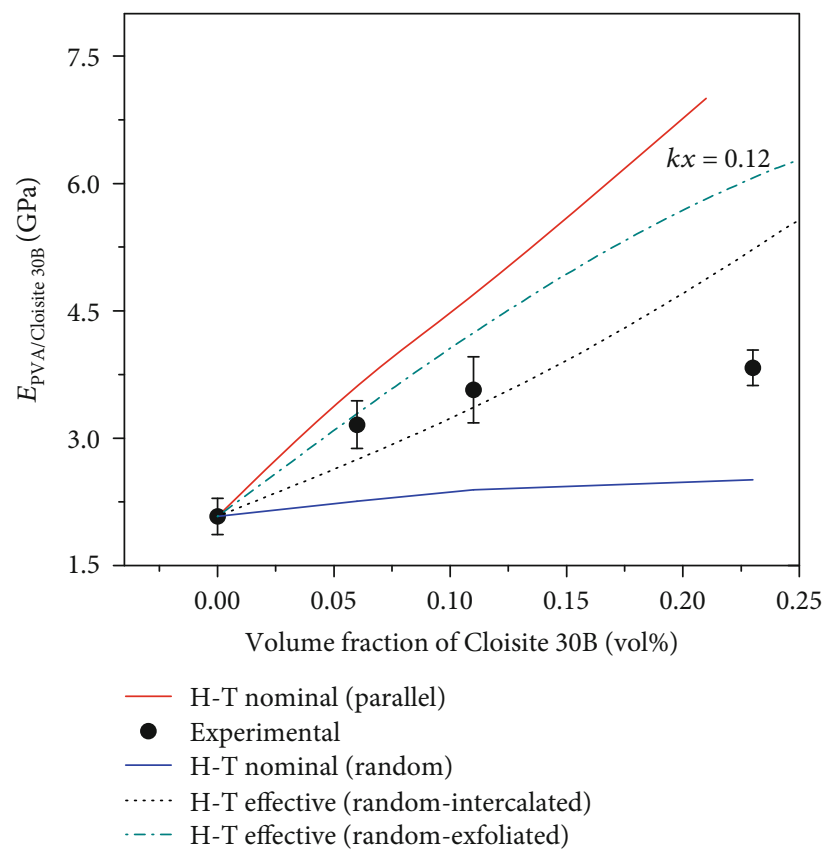

(c)

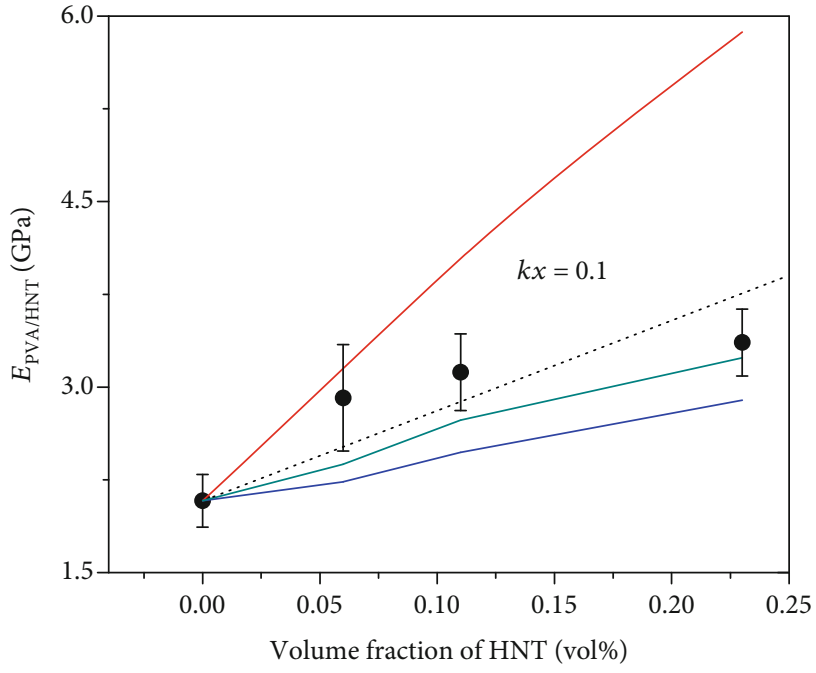

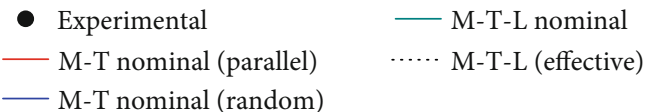

(b)

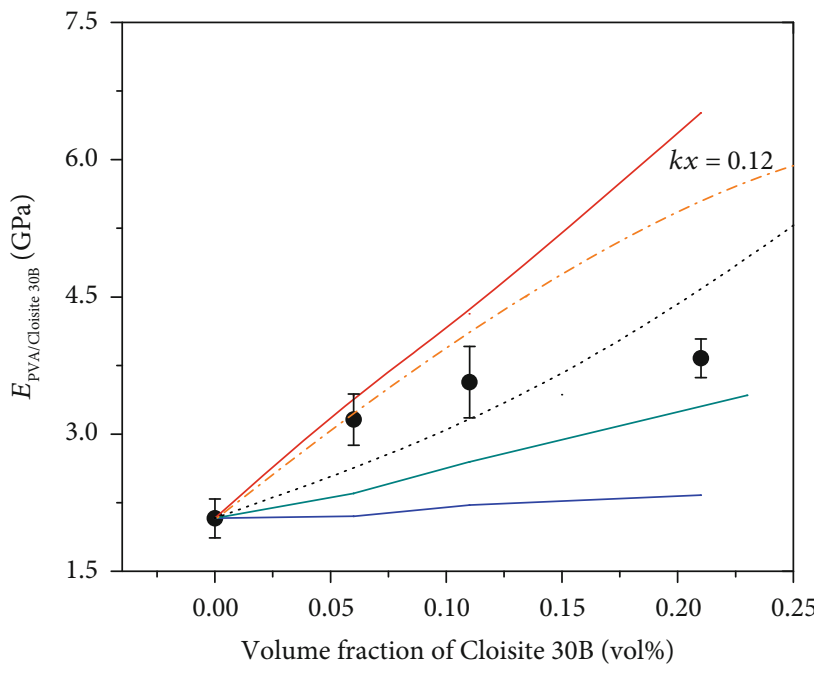

- Experimental

- M-T nominal (parallel)

- M-T nominal (random)

- M-T-L nominal

$\cdots \cdot$ M-T-L (effective-intercalated)

-.. M-T-L (effective-exfoliated)

(d)

FIgure 9: Prediction of the elastic moduli of PVA/HNT bionanocomposites: (a) Halpin-Tsai model (H-T) and (b) Mori-Tanaka model (M-T) and the combination of Mori-Tanaka model and laminate theory (M-T-L). Prediction of the elastic moduli of PVA/Cloisite 30B clay bionanocomposites: (c) Halpin-Tsai model (H-T) and (d) Mori-Tanaka model (M-T) and the combination of Mori-Tanaka model and laminate theory (M-T-L).

exfoliated at low volume fractions as opposed to predominant intercalated structures with an increase in their volume fraction, which further confirmed a mix of exfoliated and intercalated structures taking place in PVA/Cloisite 30B clay bionanocomposites. The major drawback in using conventional Halpin-Tsai model and Mori-Tanaka model lies in their common assumption that both nanofillers and polymer matrices in nanocomposites are linearly elastic and isotropic materials with uniform nanofiller dispersion and the neglect of particle-particle interactions [44]. Generally speaking, isotropic nanoparticles are in possession of very large specific surface areas on which a substantial amount of molecular chains of polymer matrices can be absorbed with the aid of hydrogen bonding or electrostatic forces, resulting in the 


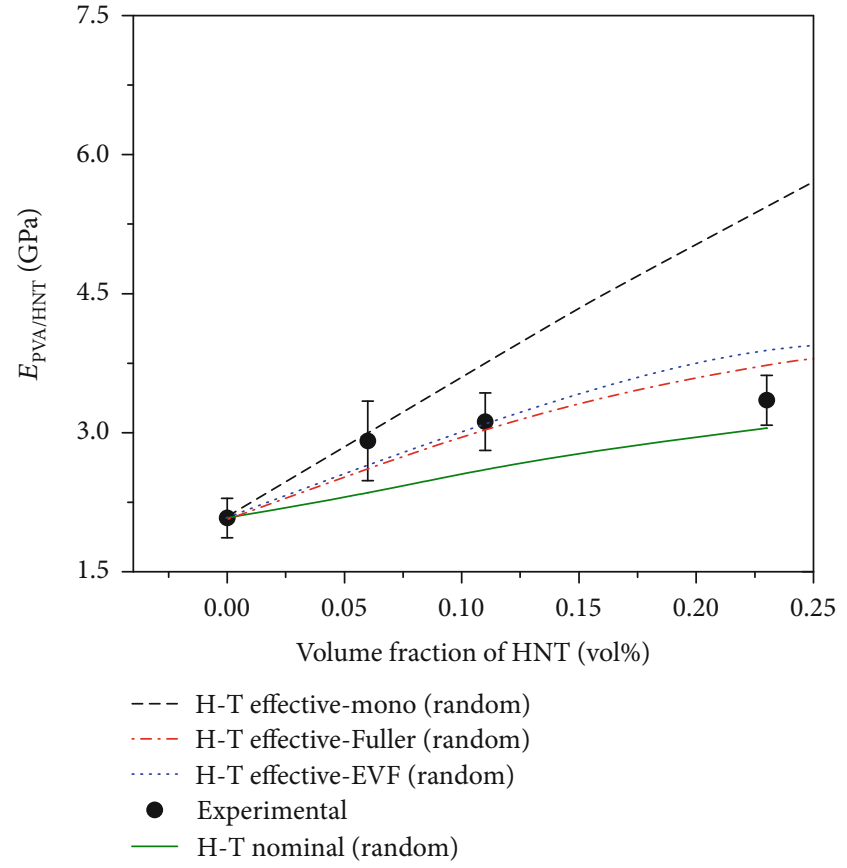

(a)

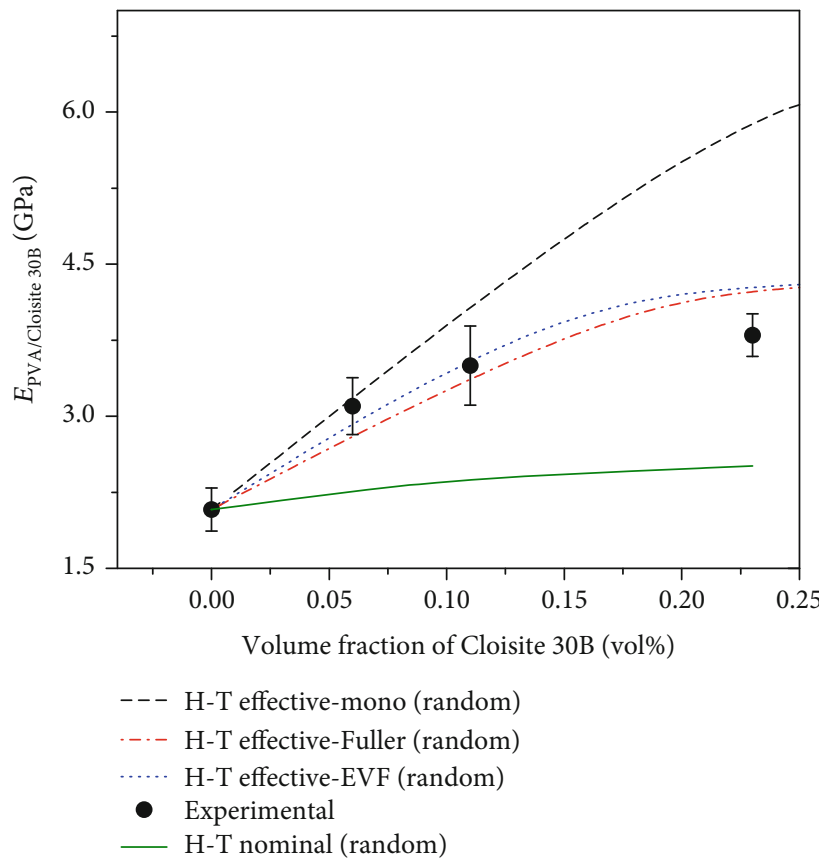

(c)

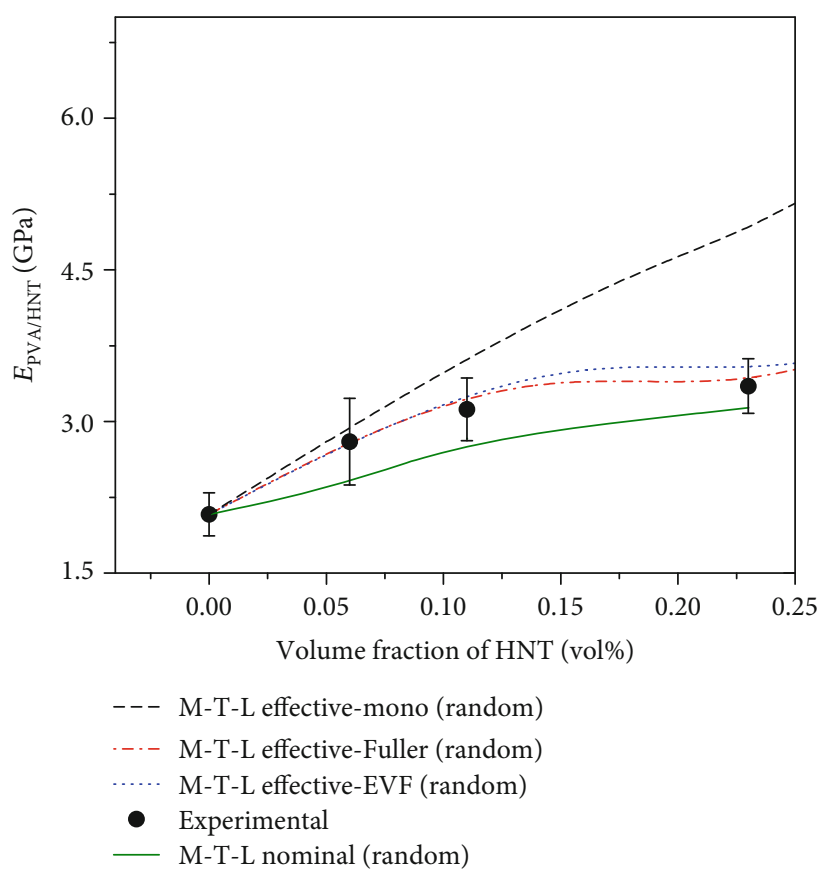

(b)

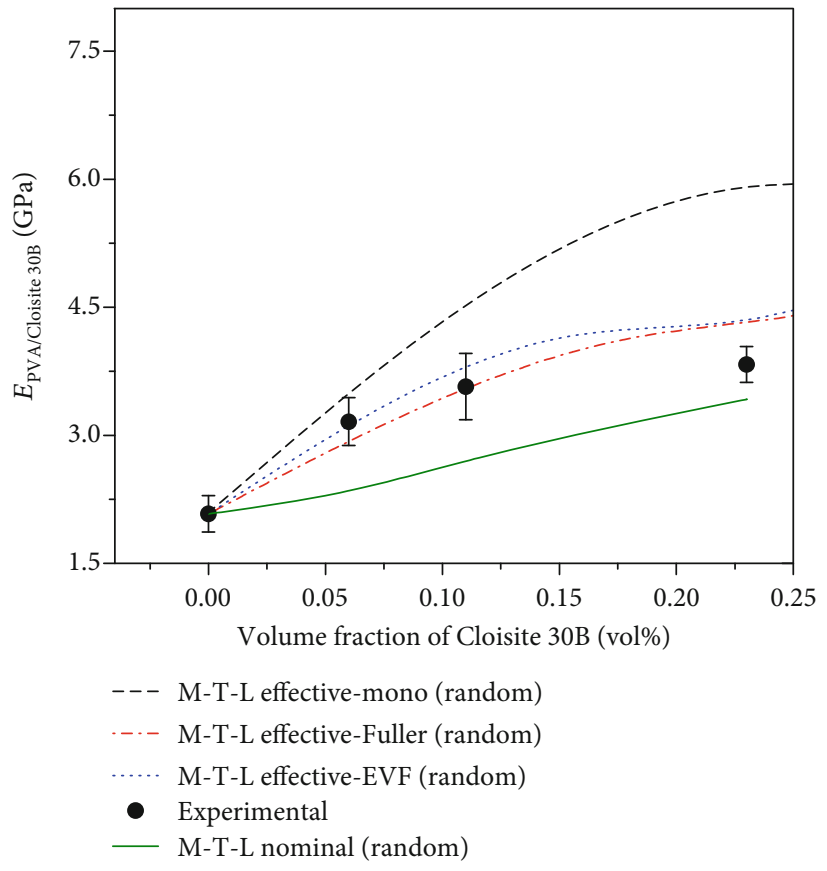

(d)

Figure 10: Prediction of the elastic moduli of PVA/HNT bionanocomposites: (a) Halpin-Tsai model (H-T) and (b) the combination of Mori-Tanaka model and laminate theory (M-T-L). Prediction of the elastic moduli of PVA/Cloisite 30B clay bionanocomposites: (c) Halpin-Tsai model $(\mathrm{H}-\mathrm{T})$ and (d) the combination of Mori-Tanaka model and laminate theory (M-T-L).

formation of interphase layers in nanocomposites. Consequently, such interphase layers behave as solid transitional material phases to restrict the mobility of other molecular chains of matrices, thus contributing positively to the total volume of reinforcements $[31,34]$. This suggested that composite theoretical models in this study should use effective volume fraction instead of nominal volume fraction for better accuracy of modelling work.

Although as mentioned earlier, the implementation of an effective volume fraction can lead to a more accurate estimation of experimental data in PVA bionanocomposites, the layer thickness of polymeric molecules absorbed onto 
TABLE 1: Modelling parameters used for PVA bionanocomposite films.

\begin{tabular}{|c|c|c|c|}
\hline Modelling parameter & PVA/HNT & PVA/Cloisite 30B clay & Ref. \\
\hline$E_{m}(\mathrm{GPa})$ & 2.08 & 2.08 & {$[45]$} \\
\hline \multirow[t]{2}{*}{$E_{p}(\mathrm{GPa})$} & $140^{\mathrm{a}}$ & $178^{\mathrm{b}}$ & $\begin{array}{l}{ }^{\mathrm{a}}[46] \\
\mathrm{b}[32]\end{array}$ \\
\hline & 208 (3 wt\% HNTs) & 109 (3 wt\% Cloisite 30B) & {$[45]$} \\
\hline \multirow[t]{3}{*}{$l_{p}(\mathrm{~nm})$} & 410 (5 wt\% HNTs) & 206 (5 wt\% Cloisite 30B) & {$[45]$} \\
\hline & 900.6 (10 wt\% HNTs) & 560 (10 wt\% Cloisite 30B) & {$[45]$} \\
\hline & & 4.6 (3 wt\% Cloisite 30B) & {$[45]$} \\
\hline \multirow[t]{3}{*}{$t_{p}(\mathrm{~nm})$} & & 15.8 (5 wt\% Cloisite 30B) & {$[45]$} \\
\hline & & 41.6 (10 wt\% Cloisite 30B) & {$[45]$} \\
\hline & 35.2 (3 wt\% HNTs) & & {$[45]$} \\
\hline \multirow[t]{2}{*}{$d(\mathrm{~nm})$} & 66.5 (5 wt $\%$ HNTs) & & {$[45]$} \\
\hline & 85 (10 wt\% HNTs) & & {$[45]$} \\
\hline$\rho_{m}\left(\mathrm{~g} \mathrm{~cm}^{-3}\right)$ & 0.39 & 0.39 & {$[45]$} \\
\hline$\rho_{p}\left(\mathrm{~g} \mathrm{~cm}^{-3}\right)$ & 1.8 & 1.98 & Material data sheets \\
\hline$t(\mathrm{~nm})$ & $\sim 7.3$ & $\sim 10.4$ & {$[45]$} \\
\hline$R_{g}(\mathrm{~nm})$ & 10 & 10 & {$[32]$} \\
\hline$v_{m}$ & 0.4 & 0.4 & {$[34]$} \\
\hline$W_{p}^{\prime \prime}$ & & 0.66 & {$[32]$} \\
\hline$d_{1}(\mathrm{~nm})$ & & 1.87 & {$[45]$} \\
\hline$d_{2}(\mathrm{~nm})$ & & 3.6 & {$[45]$} \\
\hline$N$ & & 5.6 & {$[45]$} \\
\hline$h(\mathrm{~nm})$ & & 0.98 & {$[45]$} \\
\hline$\rho_{p}^{\prime \prime}\left(\mathrm{g} \mathrm{cm}^{-3}\right)$ & & 3.1 & {$[45]$} \\
\hline$A_{T}\left(\mathrm{~m}^{2} \mathrm{~g}^{-1}\right)$ & $40.3^{c}$ & $658^{\mathrm{d}}$ & $\begin{array}{l}{ }^{\mathrm{c}}[47] \\
{ }^{\mathrm{d}}[32]\end{array}$ \\
\hline
\end{tabular}

nanofiller surfaces in terms of $k x$ may vary even in the same grade of polymers with different molecular structures and polarities [32, 34]. Our aforementioned results demonstrated that interphase features actually did not possess a uniform interphase layer thickness, and the interphase dimensions and properties could vary significantly when embedded with heterogeneous nanoparticles with different particle sizes and dimensions, as well as diverse nanomechanical properties depending on matrix-filler interactions. As a result, interphase volume fraction $\varnothing_{\text {Interphase }}$ was incorporated into two different particle systems, namely monodispersed particles and polydispersed particles by considering the Fuller and EVF gradations, respectively. Modelling parameters presented in Table 2 were substituted into equations (11) and (13), respectively, to estimate corresponding $\varnothing_{\text {Interphase }}$ values used in PVA bionanocomposites in this study. Besides, interphase volume can be calculated according to equations (5), (6), (7), and (8) with associated results being used to determine the volume fraction of nanofillers. Such recalculated volume fractions of nanoparticles with respect to the interphase effect were incorporated into Halpin-Tsai model and Mori-Tanaka model accordingly in this study and illustrated in Figure 10 (with monodispersed and polydispersed particle systems). In a consistent manner, all elastic moduli of PVA bionanocomposites with the consideration of the interphase effect in our modelling work revealed a much closer relationship with experimental data as opposed to corresponding theoretical models using both nominal and effective volume fractions without interphase. More evidently, our proposed models in a monodispersed particle system caused better curve fitting with experimental data at low volume fractions up to 0.0604 and $0.061 \mathrm{vol} \%$ for HNTs and Cloisite 30B clays, respectively, as opposed to those in a polydispersed particle system with both the Fuller and EVF gradations, but vice versa beyond 0.1109 and 0.1105 vol\%, accordingly. It was understandable, since HNTs and Cloisite 30B clays tended to be more uniformly dispersed in PVA matrices with relatively similar nanoparticle sizes (i.e., monodispersed particle system) at their low volume fraction, while typical nanoparticle agglomeration was evidently identified in better accordance with a polydispersed particle system. When a particulate gradation effect was taken into account, those predictions according to the Fuller gradation seemed to be in slightly better agreement with corresponding experimental data in PVA bionanocomposites, which might be ascribed to the theoretical assumption of finer particle dispersion taking place in EVF gradation at the same volume fraction of nanocomposites. Larger specific surface areas of 
TABLE 2: Modelling parameters measured for the calculation of $\varnothing_{\text {Interphase }}$ in PVA bionanocomposites.

\begin{tabular}{lccc}
\hline $\begin{array}{l}\text { Modelling } \\
\text { parameter }\end{array}$ & $\begin{array}{c}\text { Nanoparticle } \\
\text { content }(\mathrm{wt} \%)\end{array}$ & PVA/HNT $^{\mathrm{a}}$ & $\begin{array}{c}\text { PVA/Cloisite } \\
\text { 30B clay }\end{array}$ \\
\hline$D_{\text {eq-min }}(\mathrm{nm})$ & 3 & 64.5 & 34.1 \\
& 5 & 168.5 & 54.3 \\
$D_{\text {eq-max }}(\mathrm{nm})$ & 10 & 245.7 & 141.6 \\
& 3 & 836 & 436 \\
$D_{\text {eq-mean }}(\mathrm{nm})$ & 10 & 2460 & 1836.2 \\
$t_{\text {Interphase }} b$ & 3 & 4645 & 3141 \\
$(\mathrm{~nm})$ & 10 & 208 & 109 \\
\hline
\end{tabular}

Note. ${ }^{\mathrm{a}} D_{\text {eq-min }}, D_{\text {eq-max }}$, and $D_{\text {eq-mean }}$ are the maximum, minimum, and mean equivalent diameters of anisotropic particles, which represent the maximum, minimum, and mean equivalent lengths of HNTs, respectively, in PVA/HNT bionanocomposites according to equations (A.24)-(A.34) in Appendix A. ${ }^{\mathrm{b}}{ }_{\text {Interphase }}$ is the average interphase thickness for the model development based on the assumption that the interphase generated between nanoparticles and polymer matrices was typically considered at the filler content of $5 \mathrm{wt} \%$ in PVA bionanocomposites.

nanoparticles generally took place in the case of EVF gradation, thus resulting in increasing $\varnothing_{\text {Interphase }}$ and volume fractions of nanoparticles. However, it was not always the case in our PVA bionanocomposites especially at very high volume fractions of nanoparticles.

\section{Conclusions}

A pioneering modelling approach was successfully developed to determine the nanomechanical properties of PVA bionanocomposites reinforced with HNTs and Cloisite 30B clays, as well as $3 \mathrm{D}$ interphase dimensions and modulus in terms of interphase surface area $\mathrm{SA}_{\text {Interphase }}$ and volume $V_{\text {Interphase }}$. It was clearly shown that the interphase modulus was consistently enhanced with increasing $\mathrm{SA}_{\text {Interphase }}$ and $V_{\text {Interphase, }}$ respectively, regardless of the embedding status of nanoparticles and proposed interfaces. The interphase moduli of PVA/Cloisite 30B clay bionanocomposites appeared to be greater than those of PVA/HNT bionanocomposites based on $V_{\text {Interphase }} / V_{\text {nanofiller }}$. The nanomechanical properties and dimensions of the interphases were found to depend greatly on nanofiller dispersion states. As expected, increasing the nanofiller content inevitably decreased particle-particle spacing resulting in nanoparticle agglomeration with the visible interfacial debonding effect between nanoparticles and PVA matrices. The incorporation of an effective volume fraction and monodispersed and polydispersed particle systems with the interphase effect in conventional Halpin-Tsai model and Mori-Tanaka model was validated to be in better agreement with experimental data as opposed to those based on a nominal volume fraction of nanoparticles with the neglect of interphase features.

\section{Appendix}

\section{Calculation of Interphase Volume Fraction $\left(\varnothing_{\text {Interphase }}\right)$}

A theoretical interfacial volume fraction can be derived from the nearest-surface distribution theory [25], in which composite media are composed of 3D rigid particles and voids. $\mathrm{Lu}$ and Torquato [25] employed statistical geometries of composites and geometric probability to determine a void exclusion probability $e_{\mathrm{v}}(r)$, which is defined as the probability of a designated empty region of composite media with the radius of particle cavities $r$ at an arbitrary point. Accordingly, $e_{\mathrm{v}}(r)$ can be given by

$$
\begin{aligned}
e_{\mathrm{v}}(r) & =(1-\eta) \exp \left[-\pi \rho\left(e r+d r^{3}+g r^{3}\right)\right] \\
e & =\frac{4\left\langle R^{2}\right\rangle}{1-\eta}, \\
d & =\frac{4\langle R\rangle}{1-\eta}+\frac{8 \pi \rho\left\langle R^{2}\right\rangle^{2}}{(1-\eta)^{2}}, \\
g & =\frac{4}{3(1-\eta)}+\frac{16 \pi \rho\langle R\rangle\left\langle R^{2}\right\rangle}{3(1-\eta)^{2}}+\frac{64 m \pi^{2} \rho^{2}\left\langle R^{2}\right\rangle^{3}}{27(1-\eta)^{3}} .
\end{aligned}
$$

In practice, $e_{\mathrm{v}}(r)$ represents the expected void fraction in such a two-phase composite system [48]. $m$ is a parameter associated with the theoretical estimation of the radial distribution function in a spherical particle system. In particular, $m=2$ has been used in this study based on the CarnahanStarling approximation [28]. $\rho$ is the number density of isotropic particles with a radius $R . \eta$ can be further calculated according to equation (A.5) as follows:

$$
\eta=\rho\langle V\rangle=\rho \frac{\pi^{3 / 2}\left\langle R^{3}\right\rangle}{\Gamma(1+(3 / 2))}=\frac{4 \pi}{3} \rho\left\langle R^{3}\right\rangle,
$$

where $\langle V\rangle$ is the average volume of hard particles and $\Gamma(x)$ is the gamma function. According to quantitative stereology [49], $\eta$ denotes the volume fraction of $3 \mathrm{D}$ rigid particles.

Composite materials are supposed to consist of a packing of rigid particles and matrices $e_{\mathrm{v}}(r)$ as mentioned earlier, which can thus be considered as the matrices in a twophase composite material. When a three-phase composite material, consisting of rigid nanoparticles, matrices, and soft-shell interphases (layer thickness $r=t$ ) surrounding particles, is taken into consideration, the combination of each of the isotropic particles and associated soft-shell interphase can be regarded as a composite particle. Therefore, a threephase composite system can be simplified as a two-phase equivalent system including rigid composite particles (i.e., the original particles and the corresponding interphases), as well as matrices. Nonetheless, for such a three-phase composite system, $e_{\mathrm{v}}(t)$ is not applicable for equations (A.1) and (A.4), but it can be subjected to the geometric configuration of anisotropic particles instead. The incorporation of the 
geometric details of particles yields the modified equations given by

$$
\begin{aligned}
e_{\mathrm{v}}(t) & =(1-\eta) \exp \left[-\pi \rho\left(e t+d t^{3}+g t^{3}\right)\right], \\
e & =\frac{\langle S\rangle}{\pi(1-\eta)}, \\
d & =\frac{4\langle R\rangle}{1-\eta}+\frac{\rho\left\langle R^{2}\right\rangle}{2 \pi(1-\eta)^{2}}, \\
g & =\frac{4}{3(1-\eta)}+\frac{4 \rho\langle R\rangle\langle S\rangle}{3(1-\eta)^{2}}+\frac{m \rho^{2}\langle S\rangle^{3}}{27 \pi(1-\eta)^{3}},
\end{aligned}
$$

where $\langle S\rangle$ is the average area of rigid particles. According to equations (A.6) and (A.7), it can be clearly shown that $e_{\mathrm{v}}(t)$ depends primarily on $R, \rho$, and the surface area of isotropic particles $S$. Similarly, in an anisotropic particle system, $e_{\mathrm{v}}(t$ ) should be calculated based on the geometric details of such particles. Hence, the key step is how to determine these characteristic parameters of anisotropic particles. According to previous studies $[30,50]$, an equivalent diameter $\left(D_{\mathrm{eq}}\right)$ is widely used as an alternative dimension of anisotropic irregular particles with complex geometries. The number density of anisotropic particles can be estimated by a quantitative stereological theory [49], which is equal to the ratio of the volume fraction of a solid phase to the average volume of rigid particles, or the ratio of the specific surface area of a solid phase to the average surface area of rigid particles. In terms of $D_{\text {eq }}$, the average volume $\langle V\rangle$ and the average surface area $\langle S\rangle$ of anisotropic particles can be calculated as follows:

$$
\begin{gathered}
\langle V\rangle=\frac{\pi}{6}\left\langle D_{\mathrm{eq}}^{3}\right\rangle, \\
\langle S\rangle=\frac{\pi}{s}\left\langle D_{\mathrm{eq}}^{2}\right\rangle .
\end{gathered}
$$

The volume fraction of a solid phase with various geometries has been found to be relatively similar to that of rigid particles [30]. As a result, the number density $\left(N_{\mathrm{V}}\right)$ of anisotropic particles is given by the following stereological theory:

$$
N_{\mathrm{V}}=\frac{V_{p}}{\langle V\rangle}=\frac{S_{\mathrm{V}}}{\langle S\rangle}=\frac{6 V_{p}}{\pi\left\langle D_{\mathrm{eq}}^{3}\right\rangle},
$$

where $S_{\mathrm{V}}$ is the specific surface area of rigid anisotropic particles. By substituting equations (A.10) and (A.11) into equations (A.6)-(A.9), the $e_{\mathrm{v}}(t)$ for composite materials reinforced with anisotropic particles can be expressed as

$$
e_{\mathrm{v}}(t)=\left(1-V_{p}\right) \exp \left[-\frac{6 V_{p}}{\left\langle D_{\mathrm{eq}}^{3}\right\rangle}\left(e^{\prime} t+d^{\prime} t^{3}+g^{\prime} t^{3}\right)\right] \text {, }
$$

$$
\begin{aligned}
\varnothing_{\text {Interphase }}= & 1-V_{p}-e_{\mathrm{v}}(t)=\left(1-V_{p}\right) \\
& \cdot\left\{1-\exp \left[-\frac{6 V_{p}}{\left\langle D_{\text {eq }}^{3}\right\rangle}\left(e^{\prime} t+d^{\prime} t^{3}+g^{\prime} t^{3}\right)\right]\right\} .
\end{aligned}
$$

In a PVA bionanocomposite system, $V_{p}$ represents the nominal volume fraction of nanofillers $\left(\varnothing_{p}\right)$. As such, equation (A.14) can be rewritten as follows:

$\varnothing_{\text {Interphase }}=\left(1-\varnothing_{p}\right)\left\{1-\exp \left[-\frac{6 \varnothing_{p}}{\left\langle D_{\text {eq }}^{3}\right\rangle}\left(e^{\prime} t+d^{\prime} t^{3}+g^{\prime} t^{3}\right)\right]\right\}$,

$$
\begin{aligned}
e^{\prime}= & \frac{\left\langle D_{\text {eq }}^{2}\right\rangle}{S\left(1-\varnothing_{p}\right)}, \\
d^{\prime}= & \frac{2\left\langle D_{\text {eq }}\right\rangle}{1-\varnothing_{p}}+\frac{3 \varnothing_{p}\left\langle D_{\text {eq }}^{2}\right\rangle^{2}}{S^{2}\left(1-\varnothing_{p}\right)^{2}\left\langle D_{\text {eq }}^{3}\right\rangle}, \\
g^{\prime}= & \frac{4}{3\left(1-\varnothing_{p}\right)}+\frac{4 \varnothing_{p}\left\langle D_{\text {eq }}\right\rangle\left\langle D_{\text {eq }}^{2}\right\rangle}{S\left(1-\varnothing_{p}\right)^{2}\left\langle D_{\text {eq }}^{3}\right\rangle} \\
& +\frac{4 m \varnothing_{p}\left\langle D_{\text {eq }}^{2}\right\rangle^{3}}{3 S^{3}\left(1-\varnothing_{p}\right)^{3}\left\langle D_{\text {eq }}^{3}\right\rangle^{2}}, \\
S= & \frac{(1+1.5 \alpha)^{2 / 3}}{1+\alpha} .
\end{aligned}
$$

In a typical nanocomposite system, nanoparticles can be dispersed uniformly with relatively similar sizes; these are known as monodispersed nanoparticles [26]. On the other hand, when nanoparticles with different sizes and diameters are dispersed randomly, they are called polydispersed nanoparticles [26].

In the case of a monodispersed particle system, the parameters $e^{\prime}, d^{\prime}$, and $\mathrm{g}^{\prime}$ are expressed as follows:

$$
\begin{aligned}
& e^{\prime}=\frac{D_{\mathrm{eq}}^{2}}{S\left(1-\varnothing_{p}\right)}, \\
& d^{\prime}=\frac{2 D_{\mathrm{eq}}}{1-\varnothing_{p}}+\left[2+\frac{3 \varnothing_{p}}{S^{2}\left(1-\varnothing_{p}\right)}\right], \\
& g^{\prime}=\frac{4}{3\left(1-\varnothing_{p}\right)}+\left[\frac{1}{3}+\frac{\varnothing_{p}}{S\left(1-\varnothing_{p}\right)}+\frac{m \varnothing_{p}^{2}}{3 S^{3}\left(1-\varnothing_{p}\right)^{2}}\right],
\end{aligned}
$$


By substituting equations (A.20)-(A.22) into equation (A.15) and then letting $\lambda=t^{\prime} / D_{\text {eq }}, \varnothing_{\text {Interphase }}$, one can express the following:

$$
\begin{aligned}
\varnothing_{\text {Interphase }}= & \left(1-\varnothing_{p}\right)\left\{1-\exp \left[-\frac{6 \varnothing_{p} \lambda^{3}}{1-\varnothing_{p}}\left[\frac{1}{S \lambda^{2}}\right.\right.\right. \\
& +\frac{1}{\lambda}\left[2+\frac{3 \varnothing_{p}}{S^{2}\left(1-\varnothing_{p}\right)}\right]+\frac{4}{3}+\frac{4 \varnothing_{p}}{S\left(1-\varnothing_{p}\right)} \\
& \left.\left.\left.+\frac{4 m \varnothing_{p}^{2}}{3 S^{3}\left(1-\varnothing_{p}\right)^{2}}\right]\right]\right\},
\end{aligned}
$$

where $\lambda$ represents the geometric size factor of anisotropic particles.

On the contrary, with respect to a polydispersed particle system, it is necessary to evaluate the effect of particle size distribution (PSD) on both the volume fraction of interphases and the reinforcement efficiency of nanocomposites. The gradation of irregular aggregates can be experimentally investigated using a sieve analyser or laser particle analyser where the size of each irregular aggregate is evaluated relative to the corresponding size of spherical particles [28]. The PSD of spherical particles can be transformed into that of anisotropic particles when the equivalent diameter is defined according to previous research work [29]. In this study, two particulate gradations, namely the Fuller gradation [29] and the equal volume fraction (EVF) gradation [29, 30], were employed with their specific equations given as follows:

$$
\begin{aligned}
& F_{V}(D)=\frac{\sqrt{D}-\sqrt{D_{\text {min }}}}{\sqrt{D_{\text {max }}}-\sqrt{D_{\text {min }}}}, \\
& F_{V}(D)=\frac{\operatorname{In} D-\operatorname{In} D_{\text {min }}}{\operatorname{In} D_{\text {max }}-\operatorname{In} D_{\text {min }}},
\end{aligned}
$$

where $F_{V}(D)$ is the cumulative volume percentage of isotopic particles with their corresponding diameter of $D$, in which $D_{\max }$ and $D_{\text {min }}$ are the maximum and minimum diameters of isotopic particles, respectively. The PSD of anisotropic particles can be connected to that of the isotopic particles by substituting $D_{\text {eq }}$ into $D$, as mentioned in equation (A.25). The optimised Fuller and EVF gradations for anisotropic particles are presented as follows:

$$
\begin{aligned}
& F_{V}\left(D_{\text {eq }}\right)=\frac{\sqrt{D_{\text {eq }}}-\sqrt{D_{\text {min eq }}}}{\sqrt{D_{\text {max eq }}}-\sqrt{D_{\text {min eq }}}}, \\
& F_{V}\left(D_{\text {eq }}\right)=\frac{\operatorname{In} D_{\text {eq }}-\operatorname{In} D_{\text {min eq }}}{\operatorname{In} D_{\text {max eq }}-\operatorname{In} D_{\text {min eq }}},
\end{aligned}
$$

where $F_{V}\left(D_{\text {eq }}\right)$ should be derived to generate the number of polydispersed particles. The volume-based probability density function $f_{V}\left(D_{\text {eq }}\right)$ is determined in terms of $D_{\text {eq }}$ based upon the first-order derivative of $F_{V}\left(D_{\text {eq }}\right)$.

$$
\begin{aligned}
& f_{V}\left(D_{\text {eq }}\right)=\frac{1}{\left(\sqrt{D_{\text {max eq }}}-\sqrt{D_{\text {min eq }}}\right) \sqrt{D_{\text {eq }}}}, \\
& f_{V}\left(D_{\text {eq }}\right)=\frac{1}{\left(\operatorname{In} D_{\text {max eq }}-\operatorname{In} D_{\text {min eq }}\right) D_{\text {eq }}} .
\end{aligned}
$$

The number $d N$ of particles with various sizes in the range of $\left[D_{\text {eq }}, D_{\text {eq }}+d D_{\text {eq }}\right]$ is then calculated as follows:

$$
d N=\frac{f_{V}\left(D_{\mathrm{eq}}\right) d D_{\mathrm{eq}}}{V\left(D_{\mathrm{eq}}\right)},
$$

where $V\left(D_{\mathrm{eq}}\right)$ is the volume of anisotropic particles. Consequently, the number-based probability density function $f_{N}$ $\left(D_{\text {eq }}\right)$ for anisotropic particles is expressed as follows:

$$
f_{N}\left(D_{\text {eq }}\right)=\frac{f_{V}\left(D_{\text {eq }}\right)}{V\left(D_{\text {eq }}\right) N},
$$

and $N$ is defined by

$$
N=\int_{D_{\text {min eq }}}^{D_{\text {max eq }}} \frac{f_{V}\left(D_{\text {eq }}\right)}{V\left(D_{\text {eq }}\right)} d D_{\text {eq }} .
$$

By substituting equations (A.26) and (A.27) into equation (A.32), $f_{N}\left(D_{\text {eq }}\right)$ is given by

$$
\begin{aligned}
f_{N}\left(D_{\mathrm{eq}}\right)= & \frac{-q}{\left(D_{\text {max eq }}^{-q}-D_{\text {min eq }}^{-q}\right) D_{\text {eq }}^{q+1}} \\
& \cdot\left\{\begin{array}{l}
q=2.5 \longrightarrow \text { Fuller gradation } \\
q=3.0 \longrightarrow \text { EVF gradation }
\end{array}\right.
\end{aligned}
$$

Moreover, the $k$ th moment $\left\langle D_{\text {eq }}^{k}\right\rangle$ of the area of $f_{N}\left(D_{\text {eq }}\right)$ is given by

$$
\left\langle D_{\text {eq }}^{k}\right\rangle=\int_{D_{\text {min eq }}}^{D_{\text {max eq }}} D_{\text {eq }}^{k} f_{N}\left(D_{\text {eq }}\right) d D_{\text {eq }} .
$$

By substituting equation (A.33) into equation (A.34), $\left\langle D_{\text {eq }}\right\rangle,\left\langle D_{\text {eq }}^{2}\right\rangle$, and $\left\langle D_{\text {eq }}^{3}\right\rangle$ are obtained to determine the volume fraction of interphases for an anisotropic polydispersed particle system. In addition, the parameters required to calculate $\varnothing_{\text {Interphase }}$ in terms of maximum, minimum, and mean equivalent diameters of anisotropic particles $D_{\text {eq-min }}, D_{\text {eq-max }}$, and $D_{\text {eq-mean }}$, as well as $t_{\text {Interphase }}$, can be then measured for each type of nanofillers.

\section{Data Availability}

All data generated or analysed during this study are included in this manuscript and supplementary materials. 


\section{Conflicts of Interest}

The authors declare that they have no conflicts of interest and no financial interest related to this study.

\section{Acknowledgments}

Dr. Mohanad Mousa acknowledges the Higher Committee for Education Development in Iraq for awarding a research scholarship for his PhD studies at Curtin University. The authors are also indebted to Dr. Thomas Becker from Nanochemistry Research Institute, Curtin University, for his technical assistance in PFQNM measurements.

\section{Supplementary Materials}

PVA/HNT bionanocomposite films. Figure S1: (a) schematic diagrams of cross-sectional scanning of PVA/HNT interphases in PVA/HNT bionanocomposites along the transverse plane direction with (b) height profile and (c) adhesion profile. Figure S2: schematic diagrams of crosssectional scanning of PVA/HNT interphases in PVA/HNT bionanocomposites along (a) a longitudinal plane direction from the top view and (b) a height plane direction from a side view. Figure S3: relationship between the surface area of the outer interface $\left(\mathrm{SA}_{\text {outer interface }}\right)$ and interphase length $\left(L_{\text {Interphase }}\right)$ for PVA/HNT phases in PVA/HNT bionanocomposites. Figure S4: relationship between the surface area of the outer interface $\left(\mathrm{SA}_{\text {outer interface }}\right)$ and HNT/interphase volume (VHNT/Interphase) in PVA/HNT bionanocomposites. Figure S5: (a) schematic diagrams of cross-sectional scanning of PVA/Cloisite 30B interphases in PVA/Cloisite 30B bionanocomposites along the transverse plane direction with (b) height profile and (c) adhesion profile. Figure S6: schematic diagrams of cross-sectional scanning of PVA/Cloisite 30B interphases in PVA/Cloisite 30B bionanocomposites along (a) a longitudinal plane direction from the top view and (b) a height plane direction from a side view. Figure S7: relationship between the surface area of the outer interface $\left(\mathrm{SA}_{\text {outer interface }}\right)$ and interphase length $\left(L_{\text {Interphase }}\right)$ in PVA/Cloisite 30B clay bionanocomposites. Figure S8: relationship between the surface area of the outer interface $\left(\mathrm{SA}_{\text {outer interface }}\right)$ and Cloisite 30B/interphase volume ( $\left.V_{\text {Cloisite 30B/Interphase }}\right)$ in PVA/Cloisite 30B clay bionanocomposites. Figure S9: elastic modulus profiles based on typical datasets of 25 line scan regions (LSRs) with the best curve fitting in terms of scan distance Sd: (a) PVA/3 wt\% HNT bionanocomposites and (b) PVA $/ 3$ wt $\%$ Cloisite 30B clay bionanocomposites. (Supplementary Materials)

\section{References}

[1] M. Mousa and Y. Dong, "Strong poly(vinyl alcohol) (PVA)/bamboo charcoal (BC) nanocomposite films with particle size effect," ACS Sustainable Chemistry \& Engineering, vol. 6, no. 1, pp. 467-479, 2017.

[2] M. Mousa, Y. Dong, and I. J. Davies, "Eco-friendly polyvinyl alcohol (PVA)/bamboo charcoal (BC) nanocomposites with superior mechanical and thermal properties," Advanced Composite Materials, vol. 27, no. 5, pp. 499-509, 2017.

[3] A. Maliakal, H. Katz, P. M. Cotts, S. Subramoney, and P. Mirau, "Inorganic oxide core, polymer shell nanocomposite as a HighKGate dielectric for flexible electronics applications," Journal of the American Chemical Society, vol. 127, no. 42, pp. 14655-14662, 2005.

[4] U. Bogdanović, V. Vodnik, M. Mitrić et al., "Nanomaterial with high antimicrobial efficacy-copper/polyaniline nanocomposite," ACS Applied Materials \& Interfaces, vol. 7, no. 3, pp. 1955-1966, 2015.

[5] H. Liu and L. C. Brinson, "Reinforcing efficiency of nanoparticles: a simple comparison for polymer nanocomposites," Composites Science and Technology, vol. 68, no. 6, pp. 1502-1512, 2008.

[6] M. H. Mousa, Y. Dong, and I. J. Davies, "Recent advances in bionanocomposites: preparation, properties, and applications," International Journal of Polymeric Materials and Polymeric Biomaterials, vol. 65, no. 5, pp. 225-254, 2016.

[7] M. Mousa and Y. Dong, "Novel three-dimensional interphase characterisation of polymer nanocomposites using nanoscaled topography," Nanotechnology, vol. 29, no. 38, article 385701, 2018.

[8] C. Wei, D. Srivastava, and K. Cho, "Thermal expansion and diffusion coefficients of carbon nanotube-polymer composites," Nano Letters, vol. 2, no. 6, pp. 647-650, 2002.

[9] J. C. H. Affdl and J. L. Kardos, "The Halpin-Tsai equations: a review," Polymer Engineering and Science, vol. 16, no. 5, pp. 344-352, 1976.

[10] T. Mori and K. Tanaka, "Average stress in matrix and average elastic energy of materials with misfitting inclusions," Acta Metallurgica, vol. 21, no. 5, pp. 571-574, 1973.

[11] Y. Zare and H. Garmabi, "Attempts to simulate the modulus of polymer/carbon nanotube nanocomposites and future trends," Polymer Reviews, vol. 54, no. 3, pp. 377-400, 2014.

[12] K. Hu, M. K. Gupta, D. D. Kulkarni, and V. V. Tsukruk, "Ultra-robust graphene oxide-silk fibroin nanocomposite membranes," Advanced Materials, vol. 25, no. 16, pp. 23012307, 2013.

[13] A. Najipour and A. M. Fattahi, "Experimental study on mechanical properties of PE / CNT composites," Journal of Theoretical and Applied Mechanics, vol. 55, no. 2, pp. 719726, 2017.

[14] R. T. Tebeta, A. M. Fattahi, and N. A. Ahmed, "Experimental and numerical study on HDPE/SWCNT nanocomposite elastic properties considering the processing techniques effect," Microsystem Technologies, vol. 26, no. 8, pp. 24232441, 2020.

[15] R. S. Mohsen, N. K. Saied, Z. Ali, E. M. Hosein, and P. Hasan, "Theoretical and experimental determination of tensile properties of nanosized and micron-sized $\mathrm{CaCO}_{3} / \mathrm{PA} 66$ composites," Polymer Composites, vol. 30, no. 3, pp. 274-280, 2009.

[16] Y. Zare, "Development of simplified Tandon-Weng solutions of Mori-Tanaka theory for Young's modulus of polymer nanocomposites considering the interphase," Journal of Applied Polymer Science, vol. 133, no. 33, 2016.

[17] Y. Zare, "The roles of nanoparticles accumulation and interphase properties in properties of polymer particulate nanocomposites by a multi-step methodology," Composites Part A: Applied Science and Manufacturing, vol. 91, pp. 127-132, 2016. 
[18] H. Dwivedi, R. B. Mathur, T. L. Dhami, O. P. Bahl, M. Monthioux, and S. P. Sharma, "Evidence for the benefit of adding a carbon interphase in an all-carbon composite," Carbon, vol. 44, no. 4, pp. 699-709, 2006.

[19] J. Amraei, J. E. Jam, B. Arab, and R. D. Firouz-Abadi, "Effect of interphase zone on the overall elastic properties of nanoparticle-reinforced polymer nanocomposites," Journal of Composite Materials, vol. 53, no. 9, pp. 1261-1274, 2018.

[20] J. Amraei, J. E. Jam, B. Arab, and R. D. Firouz-Abadi, "Modeling the interphase region in carbon nanotubereinforced polymer nanocomposites," Polymer Composites, vol. 40, Supplement 2, pp. E1219-E1234, 2018.

[21] Y. Zare and K. Y. Rhee, "Effects of critical interfacial shear modulus between polymer matrix and nanoclay on the effective interphase properties and tensile modulus of nanocomposites," Construction and Building Materials, vol. 247, article 118536, 2020.

[22] H. J. M. Haroosh, "Investigating novel biopolymeric nanostructures for drug delivery," PhD thesis, Curtin University, Australia, 2014.

[23] B. Ohler, "Application Note \# 94: Practical Advice on the Determination of Cantilever Spring Constants," 2007, http:// nanoscaleworld.bruker-axs.com/nanoscaleworld/media/p/ 143.aspx.

[24] D. J. Behmer and C. P. Hawkins, "Effects of overhead canopy on macroinvertebrate production in a Utah stream," Freshwater Biology, vol. 16, no. 3, pp. 287-300, 1986.

[25] B. Lu and S. Torquato, "Nearest-surface distribution functions for polydispersed particle systems," Physical Review A, vol. 45, no. 8, pp. 5530-5544, 1992.

[26] W. Xu, Q. Duan, H. Ma, W. Chen, and H. Chen, "Interfacial effect on physical properties of composite media: interfacial volume fraction with non-spherical hard-core-soft-shell-structured particles," Scientific Reports, vol. 5, no. 1, article 16003, 2015.

[27] G. A. Mansoori, N. F. Carnahan, K. E. Starling, and T. W. Leland Jr., "Equilibrium thermodynamic properties of the mixture of hard spheres," The Journal of Chemical Physics, vol. 54, no. 4, pp. 1523-1525, 1971.

[28] Y. Gao, G. de Schutter, and G. Ye, "Micro- and meso-scale pore structure in mortar in relation to aggregate content," Cement and Concrete Research, vol. 52, pp. 149-160, 2013.

[29] W. X. Xu and H. S. Chen, "Analytical and modeling investigations of volume fraction of interfacial layers around ellipsoidal aggregate particles in multiphase materials," Modelling and Simulation in Materials Science and Engineering, vol. 21, no. 1, article 015005, 2013.

[30] W. X. Xu and H. S. Chen, "Numerical investigation of effect of particle shape and particle size distribution on fresh cement paste microstructure via random sequential packing of dodecahedral cement particles," Computers \& Structures, vol. 114-115, pp. 35-45, 2013.

[31] G. P. Tandon and G. J. Weng, "The effect of aspect ratio of inclusions on the elastic properties of unidirectionally aligned composites," Polymer Composites, vol. 5, no. 4, pp. 327-333, 1984.

[32] B. Chen and J. R. G. Evans, "Nominal and effective volume fractions in polymer-clay nanocomposites," Macromolecules, vol. 39, no. 5, pp. 1790-1796, 2006.

[33] M. A. Van Es, "Polymer-clay nanocomposites: the importance of particle dimensions, PhD thesis," Delft University of Technology, Netherlands, 2001.
[34] C. Wan and B. Chen, "Reinforcement and interphase of polymer/graphene oxide nanocomposites," Journal of Materials Chemistry, vol. 22, no. 8, pp. 3637-3646, 2012.

[35] C. Wan, M. Frydrych, and B. Chen, "Strong and bioactive gelatin-graphene oxide nanocomposites," Soft Matter, vol. 7, no. 13, pp. 6159-6166, 2011.

[36] Y. Gu, M. Li, J. Wang, and Z. Zhang, "Characterization of the interphase in carbon fiber/polymer composites using a nanoscale dynamic mechanical imaging technique," Carbon, vol. 48, no. 11, pp. 3229-3235, 2010.

[37] K. Tashiro and H. Tadokoro, "Calculation of three-dimensional elastic constants of polymer crystals. 3. $\alpha$ and $\gamma$ forms of nylon 6," Macromolecules, vol. 14, no. 3, pp. 781-785, 1981.

[38] K. Tashiro and M. Kobayashi, "Theoretical evaluation of three-dimensional elastic constants of native and regenerated celluloses: role of hydrogen bonds," Polymer, vol. 32, no. 8, pp. 1516-1526, 1991.

[39] Y. Liu, A.-L. Hamon, P. Haghi-Ashtiani et al., "Quantitative study of interface/interphase in epoxy/graphene-based nanocomposites by combining STEM and EELS," ACS Applied Materials \& Interfaces, vol. 8, no. 49, pp. 34151-34158, 2016.

[40] H. Fan, C. Hartshorn, T. Buchheit et al., "Modulus-density scaling behaviour and framework architecture of nanoporous self-assembled silicas," Nature Materials, vol. 6, no. 6, pp. 418-423, 2007.

[41] E. Alishahi, S. Shadlou, S. Doagou-R, and M. R. Ayatollahi, "Effects of carbon nanoreinforcements of different shapes on the mechanical properties of epoxy-based nanocomposites," Macromolecular Materials and Engineering, vol. 298, no. 6, pp. 670-678, 2013.

[42] D. A. Jesson and J. F. Watts, "The interface and interphase in polymer matrix composites: effect on mechanical properties and methods for identification," Polymer Reviews, vol. 52, no. 3, pp. 321-354, 2012.

[43] F. M. Blighe, K. Young, J. J. Vilatela et al., "The effect of nanotube content and orientation on the mechanical properties of polymer-nanotube composite fibers: separating intrinsic reinforcement from orientational effects," Advanced Functional Materials, vol. 21, no. 2, pp. 364-371, 2011.

[44] T. D. Fornes and D. R. Paul, "Modeling properties of nylon 6/clay nanocomposites using composite theories," Polymer, vol. 44, no. 17, pp. 4993-5013, 2003.

[45] M. Mousa, "Experimental characterisation and modelling of sustainable multiscaled bionanocomposites," $\mathrm{PhD}$ thesis, Curtin University, Australia, 2018.

[46] B. Lecouvet, J. Horion, C. D’Haese, C. Bailly, and B. Nysten, "Elastic modulus of halloysite nanotubes," Nanotechnology, vol. 24, no. 10, article 105704, 2013.

[47] P. Yuan, P. D. Southon, Z. Liu et al., "Functionalization of halloysite clay nanotubes by grafting with $\gamma$-aminopropyltriethoxysilane," The Journal of Physical Chemistry C, vol. 112, no. 40, pp. 15742-15751, 2008.

[48] S. Torquato, Random Heterogeneous Materials: Microstructure and Macroscopic Properties, Springer-Verlag, New York, 2002.

[49] E. E. Underwood, "Stereology, or the quantitative evaluation of microstructures," Journal of Microscopy, vol. 89, no. 2, pp. 161-180, 1969.

[50] W. Xu, W. Chen, and H. Chen, "Modeling of soft interfacial volume fraction in composite materials with complex convex particles," The Journal of Chemical Physics, vol. 140, no. 3, article 034704, 2014. 